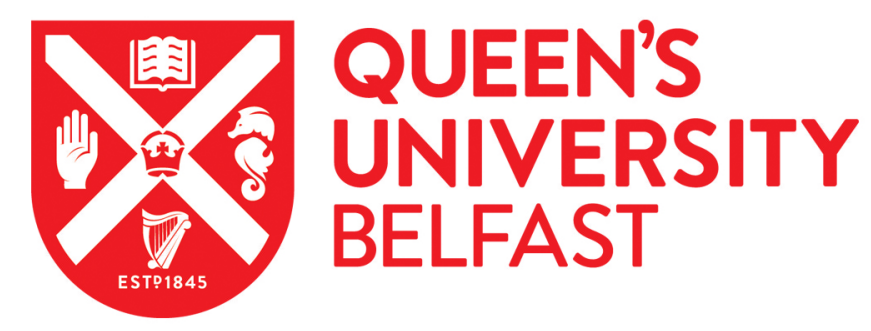

\title{
Hydrophobic functional liquids based on trioctylphosphine oxide (TOPO) and carboxylic acids
}

Byrne, E., O'Donnell, R., Gilmore, M., Artioli, N., Holbrey, J., \& Swadzba-Kwasny, G. (2020). Hydrophobic functional liquids based on trioctylphosphine oxide (TOPO) and carboxylic acids. Physical Chemistry Chemical Physics (PCCP), 22(42), 24744-24763. https://doi.org/10.1039/D0CP02605K

Published in:

Physical Chemistry Chemical Physics (PCCP)

Document Version:

Peer reviewed version

Queen's University Belfast - Research Portal:

Link to publication record in Queen's University Belfast Research Portal

Publisher rights

Copyright 2020 Royal Society of Chemistry. This work is made available online in accordance with the publisher's policies. Please refer to any applicable terms of use of the publisher.

\section{General rights}

Copyright for the publications made accessible via the Queen's University Belfast Research Portal is retained by the author(s) and / or other copyright owners and it is a condition of accessing these publications that users recognise and abide by the legal requirements associated with these rights.

Take down policy

The Research Portal is Queen's institutional repository that provides access to Queen's research output. Every effort has been made to ensure that content in the Research Portal does not infringe any person's rights, or applicable UK laws. If you discover content in the Research Portal that you believe breaches copyright or violates any law, please contact openaccess@qub.ac.uk. 


\section{Hydrophobic functional liquids based on trioctylphosphine oxide (TOPO) and carboxylic acids}

Received 00th January 20xx, Accepted 00th January 20xx DOI: $10.1039 / x 0 x \times 00000 x$

\author{
Emily L. Byrne, Ruairi O’Donnell, Mark Gilmore, Nancy Artioli, John D. Holbrey* and Małgorzata \\ Swadźba-Kwaśny*
}

Trioctylphosphine oxide (TOPO) is a hydrophobic extracting agent that is used in a number of commercially important separations of valuable solutes from aqueous streams (with examples ranging from lanthanides, through gallium, to carboxylic acids). TOPO is traditionally used as a solute in kerosene, its extraction efficiency limited by its solubility in the organic diluents. In this work, eighteen hydrogen bond donors (HBDs) were screened for their capacity to liquefy TOPO, employing strategies used to design deep eutectic solvents (DES). The selected HBDs were all active extractants in their own right and were designed to formulate solvent-free, hydrophobic, bi-functional liquid extracting agents. Some TOPO:HBD mixtures yielded hydrophobic liquids that offer potential to be extremely efficient extractants, incorporating high intrinsic concentrations of TOPO. Following this initial screening, two systems: TOPO:malonic acid and TOPO:levulinic acid, were selected for detailed physico-chemical characterisation across their complete compositional ranges. Phase diagrams, thermal stabilities and the mechanism of thermal decomposition are reported, along with densities and insights from ${ }^{31}$ P NMR spectroscopic studies. The work was concluded with a proof-of-concept demonstration of the use of the TOPO:malonic acid (2:1 mol ratio) mixture for the extraction of gallium from acidic chloride feedstock (simulated predigestate of zinc leach residue). Loading capacity of the TOPO:malonic acid extractant was three orders of magnitude greater than that of the literature benchmark, encouraging further application-oriented studies.

\section{Introduction}

The phrase deep eutectic solvent (DES) describes a eutectic mixture with significant melting point depression relative to that of its individual components (below thermodynamic lines). ${ }^{1}$ However, it should be noted that many authors adopt a much broader definition, using it to describe any twocomponent mixture that is liquid at room temperature at a given molar ratio. DES are traditionally comprised of a salt with bulky organic cation and a much smaller, Lewis-basic anion acting as hydrogen bond acceptor (HBA), and a hydrogen bond donor (HBD). ${ }^{2-6}$ First reported in 2003, an archetypal examples of DES are systems pairing choline chloride with alcohols, carboxylic acids or amides (e.g. urea) as HBD species. ${ }^{5}$ Perceived as environmentally benign and an inexpensive types of (or alternatives to) ionic liquids, DES have gained popularity as solvents for protein extraction, ${ }^{7}$ metal electrodeposition, ${ }^{2,4}$ organic synthesis ${ }^{2,4}$ and drug solubilisation. ${ }^{2}$ There has been a recent publication concerning metal recovery using these choline chloride eutectic systems, ${ }^{8}$ however, the applications that remained largely unexplored were aqueous biphasic extractions and other uses demanding hydrophobic liquids; due

\footnotetext{
a. The QUILL Research Centre, School of Chemistry and Chemical Engineering, Queen's University Belfast, David Keir Building, Stranmillis Road, Belfast, BT9 5AG, United Kingdom.Email: m.swadzba-kwasny@qub.ac.uk; j.holbrey@qub.ac.uk

Electronic Supplementary Information (ESI) available: NMR spectra, DSC and TGA thermograms and tabulated data. See DOI: 10.1039/x0xx00000x
}

to the abundance of hydrogen bonding and columbic interactions, ${ }^{9-16}$ all early DES were completely miscible with water.

A break-through came in 2015, with two parallel publications describing hydrophobic eutectics, each representing a different approach. Kroon and co-workers formulated a hydrophobic eutectic by the introduction of long alkyl chains to traditional motifs of organic halide salt combined with a carboxylic acid; combining decanoic acid with longchained quaternary ammonium salts. ${ }^{17}$ Marrucho and coworkers took a naturally-occurring and intrinsically hydrophobic component (a terpene) and combined this with organic acids (e.g. pyruvic or lauric acid) to form non-ionic eutectics based on menthol. ${ }^{18}$ Both families of hydrophobic eutectics have been explored as solvents for extraction and partitioning from aqueous sources. A range of long chain quaternary ammonium salts combined with long chain carboxylic acids or alcohols and menthol-derived hydrophobic eutectics have been examined as extracting phases for organic molecules, ${ }^{19,20,30-35}$ metal ions, ${ }^{21-}$ 23,36 pesticides, ${ }^{24}$ biomolecules, ${ }^{18,25}$ from aqueous solution as well as bioactive compounds from biomass. ${ }^{26-30}$

A major advantage of the menthol-based non-ionic hydrophobic eutectics is a relatively low viscosity (12-43 mPa.s at $\left.25^{\circ} \mathrm{C}\right)^{18}$ compared to that of the ionic hydrophobic eutectics from Kroon and co-workers (173-783 $\mathrm{mPa} \cdot \mathrm{s}$ at $25^{\circ} \mathrm{C}$ ) which can be a major advantage in application to liquid-liquid extraction. ${ }^{17}$

In our group, there is a long-standing interest in the application of trioctylphosphine oxide (TOPO) in the 
formulation of functional liquids. TOPO is an abundantly available, moderately basic, hydrophobic phosphine oxide. It is a good hydrogen bond acceptor and a good ligand, finding numerous applications as an extractant for metals (particularly lanthanides), ${ }^{31,32}$ organic acids, ${ }^{33-36}$ and phenolic species ${ }^{37-40}$ from aqueous streams. Phosphine oxides are used industrially in the TRUEX and TRPO processes for removing actinides (including uranium) from radioactive waste. ${ }^{41,42}$

Under ambient conditions TOPO is a solid, therefore in order to be used in extraction it needs to be dissolved in a hydrophobic solvent, typically kerosene. However, the relatively low solubility of TOPO in apolar organic solvents as extracting phases is a major drawback in its industrial use, limiting extraction due to low TOPO concentrations. To circumvent this obstacle, the liquid Cyanex 293 (a mixture of $\mathrm{C}_{6^{-}}$ $\mathrm{C}_{8}$ phosphine oxides) was formulated, however this utilises more expensive phosphine oxides as a liquifying components and significantly increasing the cost of the extracting medium. ${ }^{40}$ Furthermore, shorter-chain phosphine oxide components are more prone to leaching to aqueous phases.

In our previous work, TOPO has been used as a ligand, to formulate Lewis acidic liquid coordination complexes (LCCS); the long chains enhancing liquid formation and increasing hydrolytic stability of the Lewis acidic catalysts. ${ }^{43-46}$ This work inspired research into the potential to incorporate TOPO as a component of a eutectic in 2018, which would have an intrinsically high concentration of this powerful and versatile extracting agent. A similar approach was taken by Meuldijk and co-workers around the same time to extract volatile fatty acids from aqueous feedstock. ${ }^{47}$ In the work of our group, however, a TOPO:phenol eutectic was reported and successfully used to extract uranyl from a model waste stream. ${ }^{48}$ Phenol was used to liquefy TOPO, being much cheaper than phosphine oxides, and already known as a strong hydrogen bond donor to TOPO. ${ }^{37-40}$ However, considering functionality of the TOPO:phenol eutectics in extraction, phenol was merely a spectator and in addition, raises concerns about potential contamination of the treated aqueous stream with phenol.

In this work, we report bifunctional TOPO-based eutectics, characterised by very high TOPO concentrations, the potential to fine-tune extraction selectivity by selecting an appropriate HBD and of low environmental concern due to benign nature of the screened components. A range of mixtures was screened for the formation of ambient-temperature liquids, followed by an in-depth study of thermal stability and phase behaviour of two systems, and a proof-of-concept demonstration of the extracting ability of one of these mixtures. We believe that this fundamental study will underpin the development of a new and versatile family of hydrophobic extractants, benefitting from synergies in the extracting ability of both components, low cost, very high partition coefficients and no requirement for organic solvents.

\section{Experimental}

\section{Materials}

TOPO was kindly provided by Solvay ( $>97 \%)$. Hydrochloric acid $(37 \%)$, benzene, malonic acid $(99 \%)$, palmitic acid $(>99 \%)$, D-(+)-cellobiose (98\%), catechol (>99\%), gentisic acid (98\%), 2,6xylenol (99\%), 4-tertbutylphenol (99\%), levulinic acid (98\%), stearic acid, (>99\%), $( \pm$ )- $\alpha$-lipoic acid $(>98 \%)$, resorcinol $(99 \%)$, gallic acid (98\%), pyrogallol (99\%), 8-hydroxyquinoline-2carboxylic acid (98\%) and (+)-sodium L-ascorbate (98\%) were purchased from Sigma Aldrich. Gallium(III) chloride (99.999\%) was purchased from Alfa Aesar and salicylic acid (98\%) was purchased from Fluorochem. For screening studies on eutectic formation, all chemicals were used as received, with the exception of catechol which was recrystallised from hot toluene followed by sublimation on Schlenk line $\left(80^{\circ} \mathrm{C}, 10^{-2} \mathrm{mbar}, 24 \mathrm{~h}\right)$ before use. For thermophysical characterisation studies, all chemicals were dried and stored in the glove box until used (MBraun Lab Master dp, <0.6 ppm $\mathrm{O}_{2}$ and $\mathrm{H}_{2} \mathrm{O}$ ).

TOPO was dried by heating under reduced pressure on a Schlenk line $\left(60^{\circ} \mathrm{C}, 10^{-2} \mathrm{mbar}, 24 \mathrm{~h}\right.$ ). Levulinic acid was dried by heating under reduced pressure on a Schlenk line $\left(40^{\circ} \mathrm{C}\right.$, $10^{-2} \mathrm{mbar}, 48 \mathrm{~h}$ ). They were both stored in the glove box as white solids. Malonic acid was dissolved in dry ethyl acetate and dried with magnesium sulfate. The suspension was filtered at $70^{\circ} \mathrm{C}$ and the filtrate was placed on a rotary evaporator to remove solvent $\left(60^{\circ} \mathrm{C}\right)$, dried on a Schlenk line $\left(60^{\circ} \mathrm{C}, 10^{-2}\right.$ mbar, $24 \mathrm{~h}$ ) and stored in a glove box.

\section{Preparation of mixtures}

In screening experiments, TOPO was combined directly (solventless) with hydrogen bond donors shown in Table 1 at given molar ratios. The mixtures were heated to $60{ }^{\circ} \mathrm{C}$ with stirring for 2 hours, or until homogeneous liquids formed.

For detailed thermophysical characterisation, TOPO:malonic acid and TOPO:levulinic acid mixtures were prepared (solventless) by combining mole fractions of each component together across the compositional range $\left(\chi_{\text {TOPO }}=\right.$ $0.1-0.9)$ under an inert atmosphere with accuracy to $\pm 0.0003 \mathrm{~g}$ and subsequently heating the mixture to $60{ }^{\circ} \mathrm{C}$ with stirring for 2 hours or until a homogeneous liquid was obtained. Samples typically formed white solids, colourless liquids or partially solid/liquid mixtures at room temperature after preparation depending on the mole ratio of components used. Homogeneous TOPO:malonic acid liquid samples were obtained between $\chi_{\text {TOPO }}=0.55-0.67$ at ambient temperature . $\chi_{\text {TOPO }}=0.50$ was a mostly liquid sample with trace solid at ambient temperature. Homogeneous TOPO:levulinic acid liquid mixtures were obtained between $\chi_{\text {TOPO }}=0.30-0.50$ at ambient temperature. $\chi_{\text {TOPO }}=0.10-0.20$ were mostly liquid samples with a small amount of solid at ambient temperature. Samples were stored in the glove box until use.

\section{Thermogravimetric analysis}

Thermal stability and decomposition routes were examined by thermogravimetric analysis (TGA) using a TA instruments Q5000 
TGA. Tzero aluminium pans and Tzero aluminium hermetic lids were used and samples prepared within a dry, argon atmosphere within the glove box. Dynamic heating regimes were applied at $10{ }^{\circ} \mathrm{C} \mathrm{min}-1$ from room temperature to $400{ }^{\circ} \mathrm{C}$ to determine the onset of thermal decomposition, $T_{\mathrm{d}}$ (onset), for each sample across the compositional range. $T_{\mathrm{d}}$ (onset) was determined by visual determination of initial deviation of the derivative of the TG curve (DTG curve) from its baseline.

Isothermal regimes were used to determine the initial rate of decomposition and/or mass loss corresponding to a particular component of the mixture. Samples were rapidly heated $\left(50{ }^{\circ} \mathrm{C} \mathrm{min}^{-1}\right)$ to determined temperatures to limit initial decomposition and then mass loss monitored under isothermal control. The isothermal temperatures selected were within the range of the first step of decomposition, at a low enough temperature to ensure that stage 2 decomposition does not occur, but high enough for decomposition to proceed at a reasonable rate. The samples were held isothermally for $22 \mathrm{~h}$. For TOPO:malonic acid mixtures, the sample was examined at $90{ }^{\circ} \mathrm{C}$ and for TOPO:levulinic acid mixtures, at 90 and $140{ }^{\circ} \mathrm{C}$.

\section{Analysis of decomposition products}

TOPO:malonic and levulinic acid mixtures $\left(\chi_{\text {TOPO }}=0.33\right)$ were prepared in a 2-necked round bottomed flask with vacuum taps attached within a glove box, as outlined above, and stored until use. This was removed from the glove box and connected to gas rig apparatus equipped with a gas chromatography-mass spectrometer (GC-MS) and purged with argon before heating. TOPO:malonic acid samples were held isothermally at $90{ }^{\circ} \mathrm{C}$ and TOPO:levulinic acid samples were held isothermally at 90, 125 and $140{ }^{\circ} \mathrm{C}$ to achieve a reasonable decomposition rate. In situ evolved gas analysis using GC-MS was used to evaluate the volatile thermal decomposition products. Levels of $\mathrm{H}_{2}, \mathrm{H}_{2} \mathrm{O}, \mathrm{CO}_{2}$, $\mathrm{CO}$ and $\mathrm{O}_{2}$ gases were monitored throughout. Analysis of the liquid phase was performed using NMR (see below).

\section{NMR spectroscopy}

Neat liquid TOPO:malonic acid ( $\left.\chi_{\text {TOPO }}=0.50-0.67\right)$ and TOPO:levulinic acid $\left(\chi_{\text {TOPO }}=0.10-0.20\right.$ ) were examined by NMR spectroscopy. Samples were prepared in a glove box under a dry argon atmosphere and transferred directly to NMR. ${ }^{31 P}$ NMR spectra were recorded on a Bruker Avance DPX $400 \mathrm{MHz}$ spectrometer at $162 \mathrm{MHz}$ with a sealed $\mathrm{D}_{3} \mathrm{PO}_{4}$ capillary added to supply an external lock, referencing the spectra to $\mathrm{D}_{3} \mathrm{PO}_{4}$ $\left(\delta^{31} \mathrm{P}=0 \mathrm{ppm}\right)$. For ${ }^{1} \mathrm{H}(400 \mathrm{MHz})$ and ${ }^{13} \mathrm{C}(101 \mathrm{MHz}) \mathrm{NMR}$ measurements, a sealed $d_{6}$-DMSO capillary was used to supply the external lock and reference.

To determine the species formed in the liquid phase as a result of decomposition, ${ }^{13} \mathrm{C}$ NMR measurements were performed on a $400 \mathrm{MHz}$ Bruker Avance DPX spectrometer at $101 \mathrm{MHz}$. TOPO:malonic acid samples were dissolved in $d_{6}$-acetone as they were not homogeneous liquids at $\chi_{\text {TOPO }}=0.33$ at ambient temperature. TOPO:levulinic acid samples were run neat with a $d_{6}$-DMSO capillary as reference.

\section{Differential scanning calorimetry}

Phase diagrams for TOPO based functional liquids where TOPO acts as the hydrogen bond acceptor with malonic acid or levulinic acid as hydrogen bond donors were constructed using differential scanning calorimetry (DSC) and visual observation of melting point using solid liquid cell (SLC) apparatus.

The upper thermal stability limit of each mixture was first determined using TGA and then DSC measurements were performed using a TA instruments Q2000 DSC with an RCS 90 cooling system attached. Tzero aluminium pans were filled with sample (typically ca. $8 \mathrm{mg}$ ) and sealed with Tzero hermetic lids within the glove box under an argon dry atmosphere before being transferred outside the glovebox to the DSC. DSC measurements were repeated in 3 cycle runs with heating and cooling occurring at $2{ }^{\circ} \mathrm{C} \mathrm{min}-1$ between -90 and $80^{\circ} \mathrm{C}$ or below. In all cases, samples were run below their upper thermal stability limit before thermal decomposition occurred. Between heating and cooling cycles, samples were held isothermally for 5 minutes to allow the sample to thermally equilibrate before the subsequent cycle began. The maxima of all phase transitions were recorded.

\section{Visual melting point determination}

Visual melting point was determined using a solid-liquid cell apparatus. The phase observed as a function of temperature was recorded for samples $\left(3 \mathrm{~cm}^{3}\right)$ pre-loaded into a sealed Pyrex glass solid liquid cell containing a stirrer bar within the glove box. Samples were removed from the glove box, placed in a thermostated water or ethanol bath in which the thermocouple immersed in the bath, secured around the exterior of the solid liquid cell, and the temperature allowed to equilibrate for 30 minutes $\left(1{ }^{\circ} \mathrm{C}\right.$ increments near phase transitions). Stirring rate was fixed at $400 \mathrm{rpm}$. Temperatures above $0.0{ }^{\circ} \mathrm{C}$ were controlled using Julabo circulating bath and temperatures below $0.0^{\circ} \mathrm{C}$, down to $-60.0^{\circ} \mathrm{C}$, were achieved with the addition of liquid nitrogen to the surrounding ethanol bath. When the liquidus point had not been reached above $68.0-80.0^{\circ} \mathrm{C}$, a silicon oil bath was used and temperature controlled by the $\mathrm{Pt}$ 1000 temperature sensor on a Heidolph Hei-Tec heating plate. In all cases, an Omega type $\mathrm{K}(5 \mathrm{SC})$ thermocouple with a $\mathrm{HH} 802 \mathrm{U}$ thermocouple thermometer was used to determine temperature. In solid-liquid cell measurements there were two points of interest for phase change of crystalline mixtures: the temperature at which the magnetic stirrer bar started to move within the cell and the temperature at which a clear homogeneous liquid was formed on heating. Due to the liquidus point for a number of TOPO:malonic acid samples being above their thermal decomposition temperature (i.e. for $\chi_{\text {TOPO }}=$ $0.00-0.33$ ), clear yellow liquids were obtained at the liquidus point. In non-crystalline glassy samples (i.e $\chi_{\text {TOPO }}=0.60$ for TOPO:malonic acid and $\chi_{\text {TOPO }}=0.40$ for TOPO: levulinic acid), the phase change was determined on warming by ambient temperature, following previous cooling using liquid nitrogen addition to an ethanol bath as the temperature in which stirrer bar motion could be detected within the solid liquid cell. In this 
case, average heating rates were $1-2{ }^{\circ} \mathrm{C} \mathrm{min}^{-1}$. All samples were repeated twice or more.

\section{Density}

Density measurement for homogeneous liquid TOPO:malonic acid mixtures between $\chi_{\text {TOPO }}=0.55-0.67$ and TOPO:levulinic acid mixtures between $\chi_{\text {TOPO }}=0.30-0.50$ were studied. The liquid phase of TOPO:malonic acid at $\chi_{\text {TOPO }}=0.50$ and TOPO:levulinic acid mixtures between $\chi_{\text {TOPO }}=0.10-0.20$ were also sampled and measured. Density measurements were performed on an Anton Paar DMA 4500 M density meter over a temperature range of $20-50{ }^{\circ} \mathrm{C}$ in increments of $5{ }^{\circ} \mathrm{C}$. Samples were transferred to a syringe within a dry argon atmosphere and kept in the glove box until density measurements were performed.

\section{Leaching study}

Two TOPO:malonic acid liquid samples at the extremities of the homogeneous liquid range (i.e. $\chi_{\text {TOPO }}=0.55$ and 0.67 ) were selected for the study. Two samples of each composition were prepared and combined in a shaking tube with an equi-volume of deionised water (polished to $18.2 \mathrm{M} \Omega \mathrm{cm}^{-1}$ ) or a $6 \mathrm{M} \mathrm{HCl}$ aqueous phase. These mixtures were shaken on a Stuart scientific flask shaker SF1 (20 mins, ambient temperature) and subsequently centrifuged to achieve a good phase separation. Malonic acid concentration in the aqueous phase post-contact with deionised water was determined by both FT-IR and total organic carbon content (TOC). An Agilent Technologies Cary 630 FT-IR spectrometer was used to record FT-IR spectra. Shimadzu TOC-L analyser was used to quantify total organic carbon content. For FT-IR calculations, a calibration curve of malonic acid concentration in deionised water (3.25-90.00 $\left.\mathrm{g} \mathrm{L}^{-1}\right)$ was first generated by plotting aqueous malonic acid concentration against transmittance (Figure $\mathrm{S} 12 \mathrm{SI}$ ) and fitting to the linear equation ( $\left.y=\mathrm{mx}+\mathrm{c}, R^{2}=0.9981\right)$. The $R^{2}=0.9519$, derived for $6 \mathrm{M} \mathrm{HCl}$ calibration curve was found unsatisfactory, therefore leaching of malonic acid into $6 \mathrm{M} \mathrm{HCl}$ was quantified by TOC.

For TOC calculations, the amount of carbon corresponding to malonic acid $\left(\mathrm{g} \mathrm{L}^{-1}\right)$ in the aqueous phase was calculated using Eq. 1. $[\mathrm{MA}]$ is the concentration of malonic acid $\left(\mathrm{g} \mathrm{L}^{-1}\right), \mathrm{TOC}_{\text {raw }}$ $(\mathrm{ppm})$ is the raw concentration of carbon in the sample, TOC $(\mathrm{ppm})$ is the concentration of carbon in a blank water sample, $d$ is the dilution factor, $\mathrm{RMM}_{\mathrm{MA}}\left(\mathrm{g} \mathrm{mol}^{-1}\right)$ is the relative molecular mass of malonic acid and $\mathrm{RMM}_{\text {total carbon }}\left(\mathrm{g} \mathrm{mol}^{-1}\right)$ is the relative molecular mass of the total number of carbons present in the sample.

$$
[M A]=\frac{T O C_{\text {raw }}-T O C_{W} \cdot d \cdot R M M_{M A}}{(1000) \cdot R M M_{\text {total carbon }}} \quad \text { Eq.1. }
$$

\section{Typical extraction procedure}

De-ionised water used to make $\mathrm{HCl}$ stock solutions was collected from a Barnsted deionisation system, polished to $18.2 \mathrm{M} \Omega \mathrm{cm}^{-1}$. $\mathrm{HCl}$ stock solutions were prepared in volumetric flasks at molar concentrations between $1-8 \mathrm{M} \mathrm{HCl}$. Acidic chloride stock solutions of gallium were prepared by weighing gallium(III) chloride into a 2-necked round bottom flask in a dry, argon environment within the glove box. This was then sealed and transferred to Schlenk line apparatus where a steady flow of argon was flowed over the flask and the $\mathrm{HCl}$ stock added dropwise with ice bath cooling. Following dilution with de-ionised water, the gallium content in the aqueous phase was determined by inductively coupled plasma (ICP) using an Agilent Technologies 5100 ICP-OES spectrometer.

For the partitioning studies, a given volume of extractant (i.e. $\chi_{\text {TOPO }}=0.67$ TOPO: malonic acid) was added to a centrifuge tube, pre-equilibrated with an equivolume of $\mathrm{HCl}$ stock solution with a concentration corresponding to that of the stock used for the extraction of gallium, and then contacted with an equivolume of acidic chloride gallium stock (unless stated). When replicating the literature benchmark at $6 \mathrm{M} \mathrm{HCl}, 31$ $0.004 \mathrm{M}$ TOPO diluted in benzene was prepared as the extractant phase. This extractant phase was first preequilibrated by contact with an equivolume of $\mathrm{HCl}$ stock solution with a concentration corresponding to that of the stock used for the extraction of gallium. It was then contacted with an equivolume of acidic chloride gallium stock (0.00568 $\mathrm{M} \mathrm{GaCl}_{3}$ ).

Both pre-contact and extraction times in all cases were 10 mins and the biphasic samples were mixed using a mechanical shaker (Burrell, model 75). After pre-contact and extraction, samples were centrifuged, and the aqueous phase separated from the extracting phase. Gallium content present in the aqueous phase post extraction was determined by ICP-OES following dilution (if required).

The gallium extraction efficiency (\%) was calculated using Eq. 2. from the difference in [Ga] ${ }_{(\mathrm{aq})}$ before and after contacting with the extraction phase, assuming no significant changes in liquid volumes and equilibrium mass transfer.

Extraction efficiency $=\left[100-\frac{\left([\mathrm{Ga}]_{\left.(\mathrm{aq}, \mathrm{final})^{* 100}\right)}\right.}{[\mathrm{Ga}]_{(\mathrm{aq}, \text { init })}}\right]$

$[\mathrm{Ga}]_{(\mathrm{aq}, \mathrm{init})}$ and $[\mathrm{Ga}]_{(\mathrm{aq}, \text { final) }}$ correspond to the initial and final gallium concentration in the aqueous phase respectively.

\section{Results and discussion}

In a preliminary screening to determine which mixtures with TOPO formed room-temperature liquids, a range of hydrogen bond donors (HBDs) were examined. All the materials tested are inexpensive, off-the-shelf chemicals (with the exception of 8-hydroxyquinoline-2-carboxylic acid), with relevance to separations in which TOPO has been used as an extractant. Table 1 lists all HBD-TOPO mixtures, their compositions expressed as molar ratio of TOPO ( $\left.\chi_{\text {TOPO }}\right)$, and their apparent physical state, at room temperature and in a chilled state. For the purpose of the screening tests, the materials were used as received, without drying. 


\section{ARTICLE}

Table 1. Mixtures of TOPO with hydrogen bond donors (HBDs) and their physical appearance at ambient temperature and at $8.5^{\circ} \mathrm{C}$. All HBDs used were solid at ambient temperature. $T_{\mathrm{m}(\mathrm{TOPO})}=52^{\circ} \mathrm{C}$

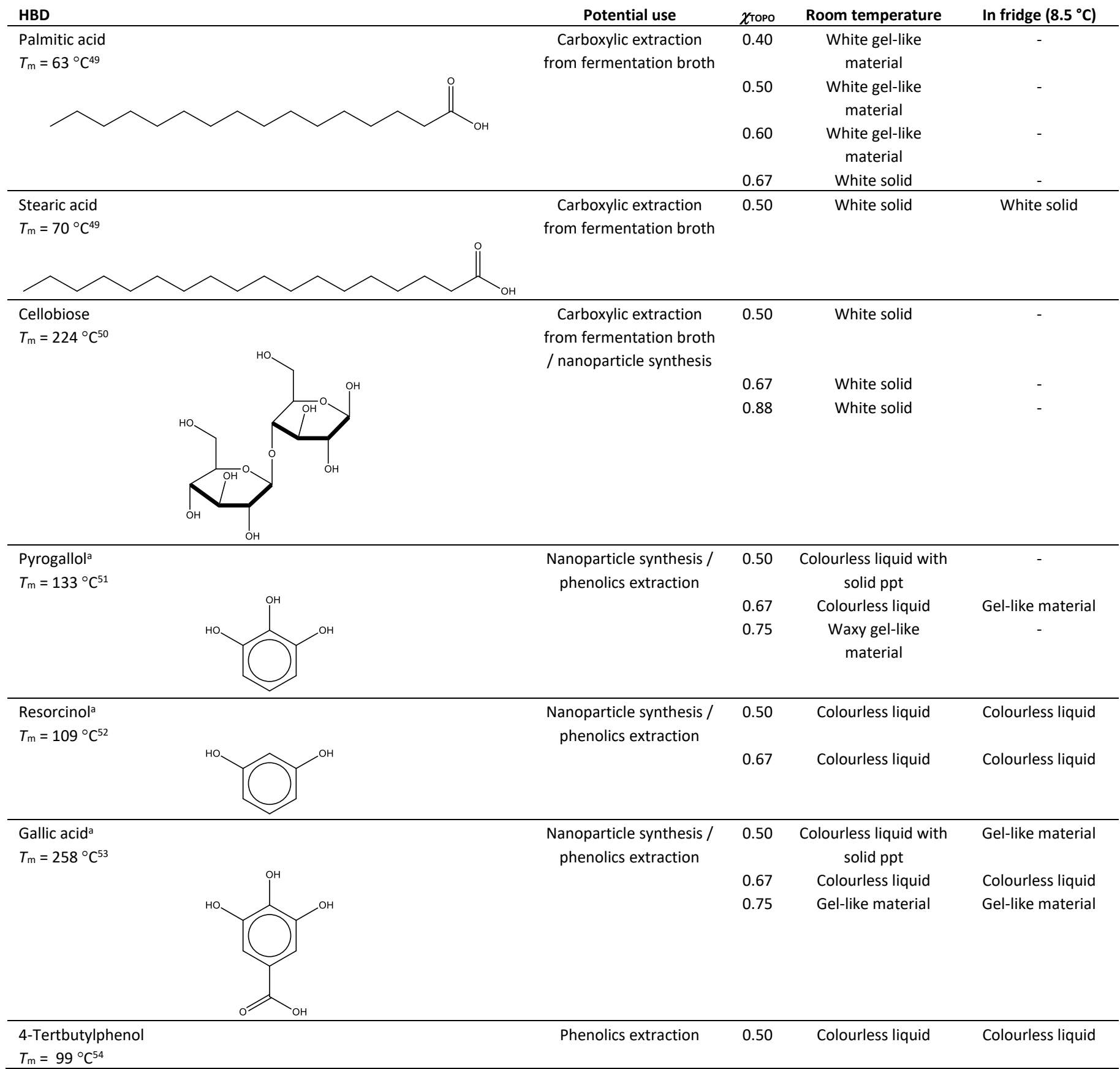




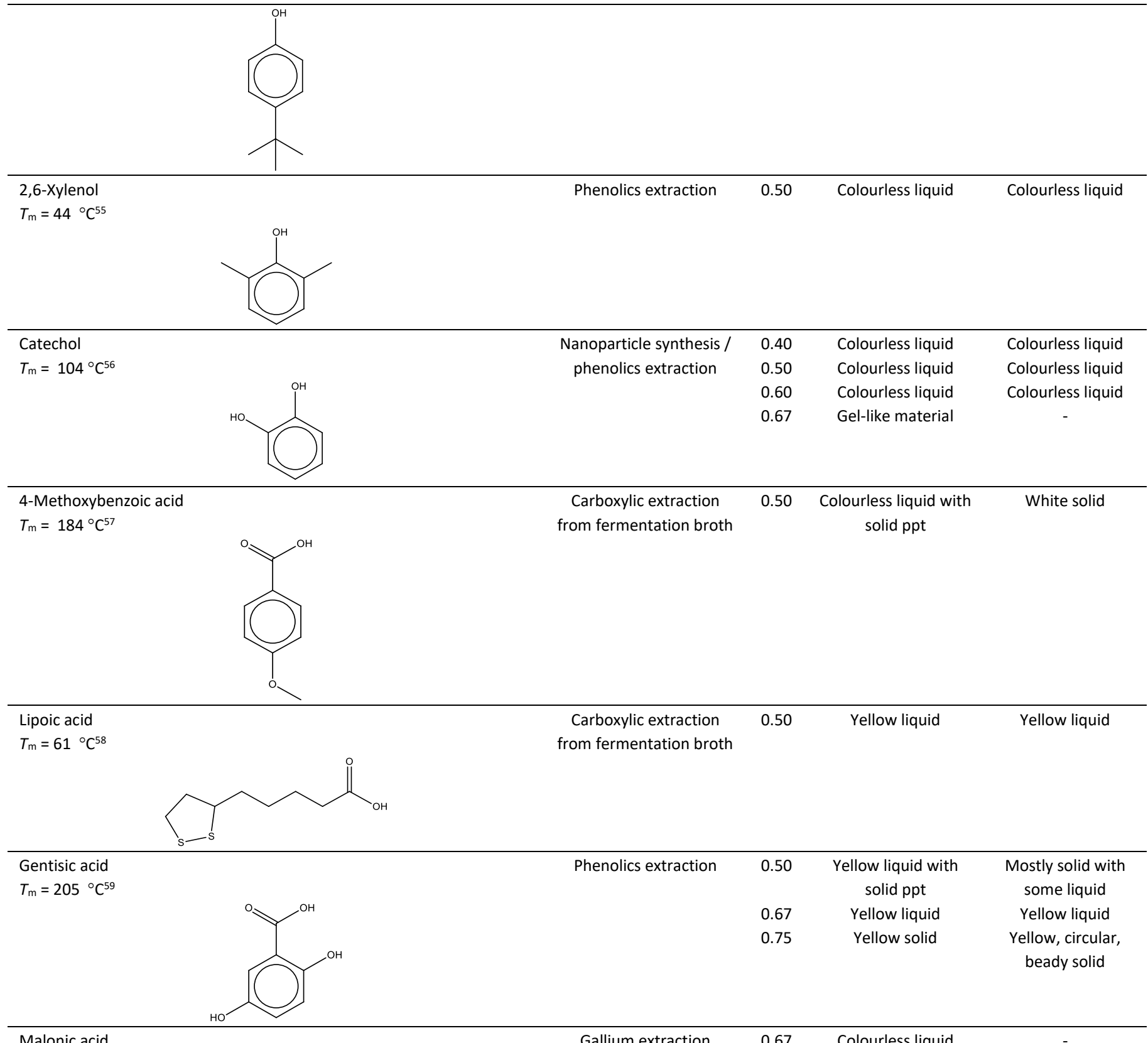

\section{$T_{\mathrm{m}}=137^{\circ} \mathrm{C}$ (lit. $\left.136^{\circ} \mathrm{C}\right)^{60}$}

Gallium extraction

$0.67 \quad$ Colourless liquid

\section{$\overbrace{}^{2}$}

Levulinic acid

$T_{\mathrm{m}}=32^{\circ} \mathrm{C}\left(\text { lit. } 32^{\circ} \mathrm{C}\right)^{6}$

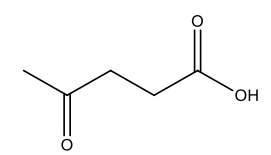

\section{Salicylic acid}

$T_{\mathrm{m}}=158{ }^{\circ} \mathrm{C}^{62}$

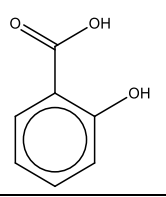

8-hydroxyquinoline-2-carboxylic acid

Carboxylic extraction $\quad 0.50 \quad$ Colourless liquid $\quad$ Colourless liquid
from fermentation broth
Gallium extraction /

phenolics extraction
0.50

$0.67 \quad$ White solid 
$T_{\mathrm{m}}=216{ }^{\circ} \mathrm{C}^{63}$<smiles>O=C(O)c1ccc2cccc(O)c2n1</smiles>

0.67
Yellow gel-like

material

Yellow gel-like material

Diphenylacetic acid

$T_{\mathrm{m}}=148{ }^{\circ} \mathrm{C}^{64}$

Gallium extraction

0.50

Colourless liquid

Colourless liquid

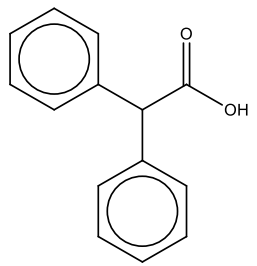

a Samples turned increasingly pink to brown after a few hours/days; ppt = precipitate

Long chain unsaturated fatty acids (palmitic and stearic) gave waxy solids, induced by long alkyl chains of both components. Cellobiose (a disaccharide) produced a solid mixture rather than low melting liquids. Several phenolics that were screened - pyrogallol, resorcinol and gallic acid - all initially formed colourless liquids consistent with the previous results obtained with phenol. However, they all turned pink and subsequently brown over several days, which is likely to be due to oxidation to $\sigma$-benzoquinone (red) and subsequent reactions between $\sigma$-benzoquinone and remaining polyphenol to form coloured polymers comparable to the browning effect in fruit. ${ }^{65-68}$ Nevertheless, a number of aromatic carboxylic acids, hydroxoacids and phenols gave colourless or yellow liquids at room temperature (Table 1 ).

Mixtures that formed room-temperature liquids in the tested molar ratio, all have interesting potential applications. The combination of TOPO (a capping agent in nanoparticles synthesis) and catechol (a reducing agent) could be used as a medium for the synthesis of nanoparticles. This mixture appeared visually stable over prolonged storage, in contrast to similar mixtures with resorcinol, pyrogallol and gallic acid. However, freshly-made mixtures with the latter HBDs also could be investigated, taking advantage from TOPO (a weak base) enhancing their reducing ability.

The formation of liquid mixtures with phenolics, such as salicylic acid, gentisic acid, or 2,6-xylenol, suggests that neat TOPO could be used as a wide-range phenol extractant, forming TOPO-phenolic eutectics that would phase-separate from the aqueous phase (for example wastewater streams). The same strategy could be explored for the separation of levulinic and lipoic acids from fermentation broths.

Acetylacetone (acac) ${ }^{69}$ and other $\beta$-diketones ${ }^{70}$ have been shown to extract gallium from aqueous basic sources, ${ }^{71}$ whereas TOPO diluted in hydrocarbon diluents (e.g. benzene) has been shown to extract gallium from acidic chloride sources. ${ }^{31,72,73}$ The mixtures of TOPO with making several HBDs: malonic acid, 8-hydroxyquinoline-2-carboxylic acid and diphenylacetic acid, all formed room-temperature liquids when combined with TOPO, highlighting their potential to form a TOPO-rich gallium extracting agent. Whereas the high cost of 8 hydroxyquinoline-2-carboxylic acid makes it unsuitable for industrial use, the combination of the low cost and $\beta$-carbonyl functionality in malonic acid makes it an industrially viable metal chelating agent.

Having identified a number of promising candidates, two unsaturated dicarboxylic acid systems were selected for further study, based on malonic and levulinic acids (Figure 1).

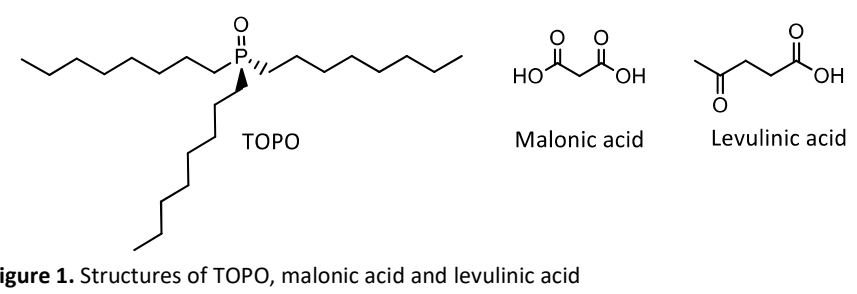

Both malonic acid and TOPO can act as ligands (complexing agents) for gallium. However, they have preferences for different gallium species, therefore work best at different $\mathrm{pH}$ ranges, and it was hoped that their combination would result in a very robust extraction system. With regards to levulinic acid, it is the main product of the liquefaction of lignocellulosics occurring through acidic solvolysis or hydrolysis, ${ }^{74}$ and is now recognised as one of the most important platform chemicals. ${ }^{74-}$ 76 TOPO (30\%) in methylisobutylketone (MIBK) has been used to extract levulinic acid from aqueous sulphuric acid feedstocks, ${ }^{34}$ and this study could pave way to a simplified approach with no auxiliary chemicals required.

Before in-depth studies were commenced, a rudimentary test for water miscibility was carried out across the range of liquid TOPO:malonic acid and TOPO:levulinic acid systems. In all cases they readily phase-separated, forming liquid-liquid biphases with water and aqueous hydrochloric acid (Figure 2). 

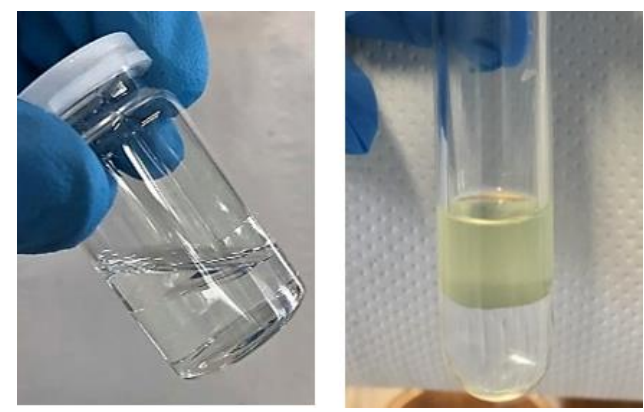

Figure 2. Left: TOPO:malonic acid $\left(\chi_{\text {TOPO }}=0.67\right)$ and water, forming a biphasic system with the TOPO:malonic acid eutectic as the less dense upper phase and water as the more dense, lower phase. Right: TOPO:malonic acid ( $\left.\chi_{\text {TOPO }}=0.67\right)$ and $6 \mathrm{M} \mathrm{HCl}$ forming a biphase with TOPO:malonic acid eutectic as the less dense upper phase and aqueous $\mathrm{HCl}$ as the more dense, lower phase. A yellow colour was added to help with visual distinction of the phases

\section{Thermal stability}

Thermal decomposition of TOPO:acid mixtures, as well as pure components, was studied using a dynamic TGA $\left(10^{\circ} \mathrm{C} \mathrm{min}^{-1}\right)$, followed by isothermal studies.

TOPO:malonic acid. Dynamic TGA scans for the TOPO:malonic acid system $\left(\chi_{\text {TOPO }}=0.00-1.00\right)$ were plotted in Figure 3 with the thermal decomposition onset temperatures $\left(T_{\mathrm{d}}\right)$ and second stage of thermal decomposition onset $\left(T_{2}\right)$ listed in Table 2. For the ease of analysis, changes in $T_{\mathrm{d}}$ and $T_{2}$ were plotted as a function of composition ( $\chi_{\text {TOPO }}$ ) in Figure 4 . Whereas both TOPO and malonic acid decomposed in a one-step process, thermal decomposition of their mixtures occurred with two distinct steps. In all mixtures, the first decomposition step was typically complete by $c a .200^{\circ} \mathrm{C}$, followed by the second step with $>225^{\circ} \mathrm{C}$ onset (see TGA and DTG example in Figure S18). The thermal decomposition was complete around $340-375^{\circ} \mathrm{C}$ (Figure 3).

Decomposition temperatures of neat TOPO and neat malonic acid, determined from the onset of mass loss, were determined to be $T_{\mathrm{d}}=203.6$ and $133.1{ }^{\circ} \mathrm{C}$, respectively (red squares in Figure 4). Kotova et al. found that the onset of TOPO thermal decomposition occurs at $149.9{ }^{\circ} \mathrm{C}$ using a Q-1500 derivatograph within a nitrogen atmosphere and using a scan rate of $10{ }^{\circ} \mathrm{C} \mathrm{min}-1.77$ This, however, does not align with our findings, which suggest that TOPO is thermally stable at temperatures up until $203.6{ }^{\circ} \mathrm{C}$. The onset for mass loss from malonic acid corresponds with the literature values from Stanford et al. of $120-140{ }^{\circ} \mathrm{C} .{ }^{78}$ All mixtures decomposed in a two-step process, and $T_{\mathrm{d}}$ values were determined from the onset of mass loss in the first decomposition step (black squares in Figure 4). Mixtures decomposed at slightly lower temperatures than neat malonic acid, in the range $T_{\mathrm{d}}=82.0-113.1{ }^{\circ} \mathrm{C}$. For acid-rich samples, thermal stability decreased with increasing $\chi_{\text {TOPO, }}$ reaching minimum at $\chi_{\text {TOPO }}=0.33\left(82.0^{\circ} \mathrm{C}\right)$, where there is a molar ratio of two malonic acids per TOPO molecule. With further increase in TOPO mole fraction, the $T_{\mathrm{d}}$ values increased slightly.

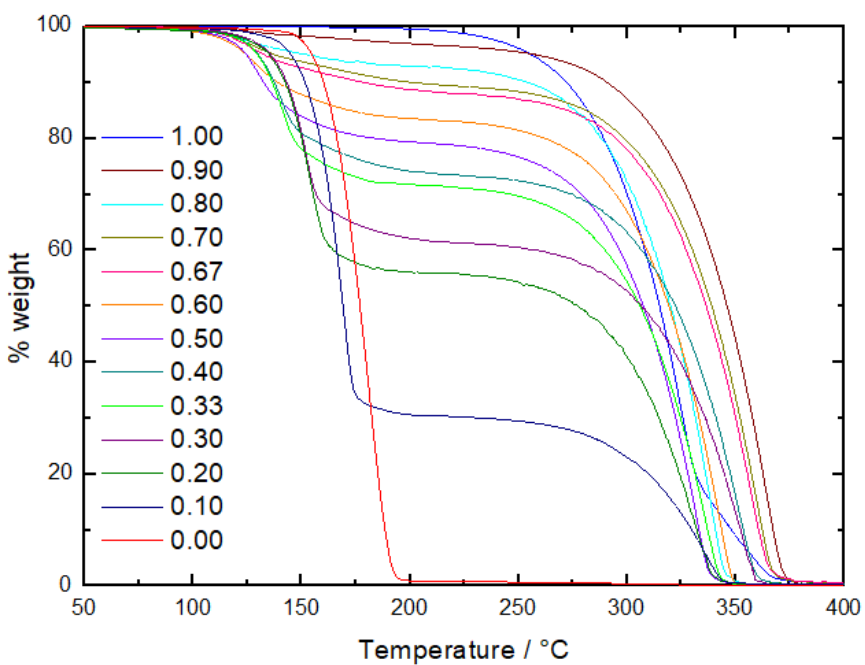

Figure 3. Mass loss profile of TOPO:malonic acid mixtures under TGA dynamic heating regime $\left(10^{\circ} \mathrm{C} \mathrm{min}-1\right)$ indicating two stage mixture decomposition

Table 2. Onset of thermal decomposition $\left(T_{\mathrm{d}}\right)$ and second thermal decomposition step $\left(T_{2}\right)$ for TOPO:malonic acid mixtures across whole compositional range

\begin{tabular}{ccc}
$\chi_{\text {TOPO }}$ & $\boldsymbol{T}_{\mathrm{d}}$ (onset) $/{ }^{\circ} \mathbf{C}$ & $\boldsymbol{T}_{\mathbf{2}} /{ }^{\circ} \mathbf{C}$ \\
\hline 1.00 & 204 & - \\
0.90 & 103 & 235 \\
0.80 & 99 & 227 \\
0.70 & 92 & 236 \\
0.67 & 90 & 239 \\
0.60 & 89 & 233 \\
0.50 & 86 & 231 \\
0.40 & 83 & 237 \\
0.33 & 82 & 232 \\
0.30 & 99 & 236 \\
0.20 & 100 & 232 \\
0.10 & 113 & 239 \\
0.00 & 133 & - \\
\hline
\end{tabular}

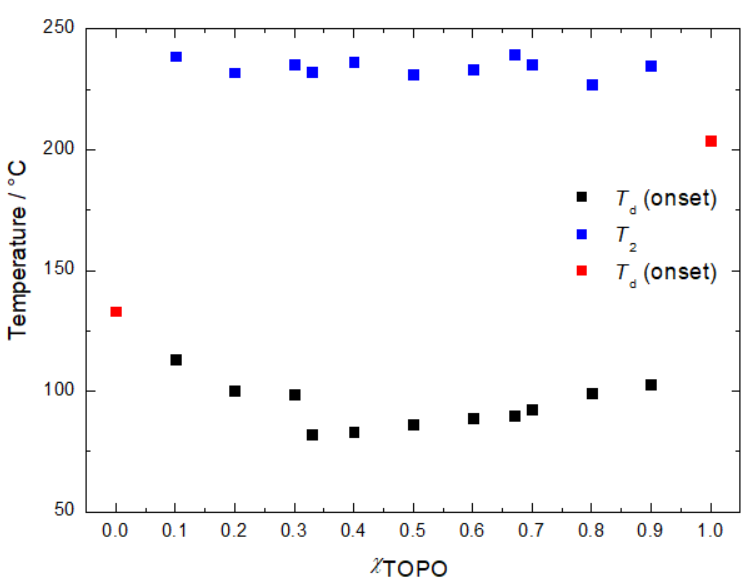

Figure 4. Onset of mass loss in thermal decomposition stages one (black squares) and two (blue squares) in TOPO:malonic acid mixtures and neat components (red squares). Described as thermal decomposition ( $T_{\mathrm{d}}$ onset) and onset of mass loss in the second step $\left(T_{2}\right)$ as a function of TOPO mole ratio under TGA dynamic heating at $10^{\circ} \mathrm{C} \mathrm{min}^{-1}$

To gain insight into the mechanism, the thermal decomposition of the $\chi_{\text {TOPO }}=0.33$ mixture was studied in detail. From isothermal TGA $\left(22 \mathrm{~h}, 90^{\circ} \mathrm{C}\right.$, Figure 5), measured at a 
temperature close to the beginning of the first mass loss event, approximately $37 \%$ mass is lost after ca. 300 mins corresponding to loss of malonic acid fraction in the first step (35\% of the sample mass). The remaining $63 \%$ of the sample roughly corresponds to the TOPO content and decomposes in the second step (65\% of the sample mass, see Figure S16 SI). This is consistent with the pattern observed from the initial dynamic TGA (Figure 3), where an approximate $29 \%$ mass loss is seen in the first step (some overlap between the decomposition of TOPO and malonic acid is justifiable under dynamic conditions). The initial decomposition rate in the first $3 \mathrm{~h}$ of the isothermal experiment (Figure 5) was calculated to be $5.8 \% \mathrm{~h}^{-1}$.

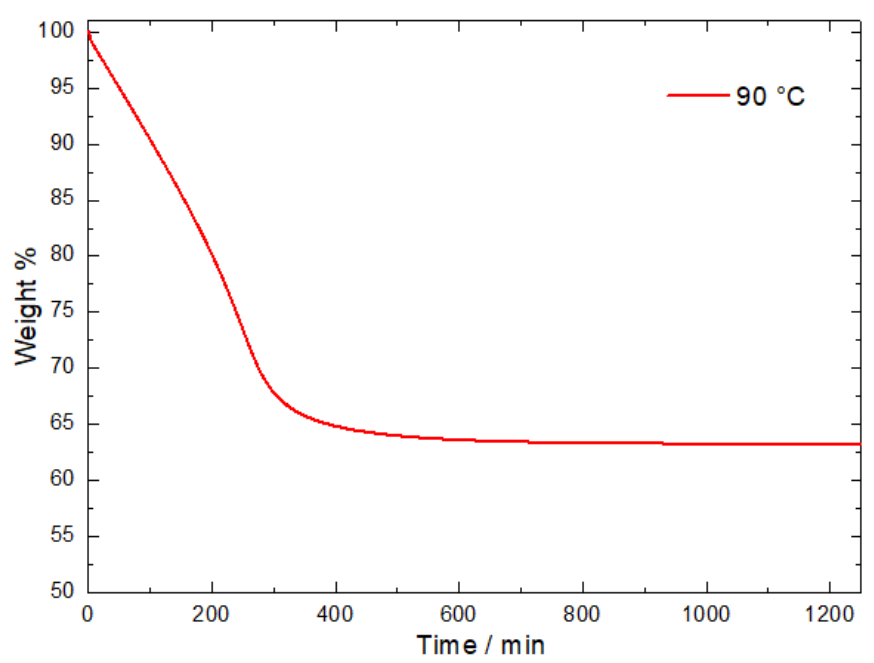

Figure 5. Mass loss profile of $\chi_{\text {TOPO }}=0.33$ TOPO:malonic acid isothermal at $90^{\circ} \mathrm{C}$. Initia heating rate $50^{\circ} \mathrm{C} \mathrm{min}^{-1}$

To investigate the chemical composition of both gas and liquid, the same experiment was carried out at a larger scale $\left(3 \mathrm{~cm}^{3}\right.$ of the $\chi_{\text {TOPO }}=0.33$ mixture was stirred at $90{ }^{\circ} \mathrm{C}$, under a flow of argon). The composition of the gas phase was monitored using in situ GC-MS, and composition of the liquid phase was probed after $1 \mathrm{~h}$ with ${ }^{1} \mathrm{H}$ and ${ }^{13} \mathrm{C}$ NMR spectroscopy. As the sample was held at $90^{\circ} \mathrm{C}$, bubbles were observed to form, the mixture turned cloudy, and there was a small amount of white crystalline material accumulated around the top of the roundbottomed flask. ${ }^{13} \mathrm{C}$ NMR spectroscopy confirmed the white powder to be malonic acid (Figure S24 SI).

When sampling, there was a notable, pungent smell of vinegar from the decomposing sample, and ${ }^{13} \mathrm{C}$ NMR spectrum (Figure S22 SI) revealed the presence of acetic acid in the mixture after $1 \mathrm{~h}$. Qualitative GC-MS detected large amounts of $\mathrm{CO}_{2}$, as well as traces of $\mathrm{CO}$ and $\mathrm{H}_{2} \mathrm{O}$, in the gas phase (Figure $\mathrm{S} 19 \mathrm{SI}$ ). These results are aligned with decomposition of malonic acid via decarboxylation, producing acetic acid and carbon dioxide (Eq. 3). ${ }^{78-83}$ This decomposition pathway has recently been reported also in choline chloride:malonic acid eutectics. ${ }^{84}$

$$
\mathrm{CH}_{3}(\mathrm{COOH})_{2} \rightarrow \mathrm{CH}_{3} \mathrm{COOH}+\mathrm{CO}_{2} \quad \text { Eq. } 3 .
$$

Furthermore, trace amounts of detected $\mathrm{CO}$ and $\mathrm{H}_{2} \mathrm{O}$ result most likely from the secondary decomposition of acetic acid (Eq. 4 and Eq. 5). ${ }^{85}$

$$
\begin{aligned}
& \mathrm{CH}_{3} \mathrm{COOH} \rightarrow \mathrm{CH}_{4}+\mathrm{CO} \quad \text { Eq. } 4 \text {. } \\
& \mathrm{CH}_{3} \mathrm{COOH} \rightarrow \mathrm{CH}_{2} \mathrm{CO}+\mathrm{H}_{2} \mathrm{O} \text { Eq. } 5 \text {. }
\end{aligned}
$$

This pattern of mass loss via thermal decomposition (decarboxylation), combined with sublimation and evaporation (evidenced by malonic acid crystallising at the top of the flask), is common in many organic acids. ${ }^{82}$ Compositions with low TOPO loading, up to $\chi_{\text {TOPO }}=0.33$, are not homogenous at the temperature of their decomposition (see the phase diagram, Figure 11). It can be envisaged that malonic acid that is phaseseparated from the mixture is free to sublime; with increased TOPO content, all malonic acid is hydrogen-bonded to TOPO and base-catalysed decarboxylation is dominant.

TOPO:levulinic acid. Dynamic TGA scans for the TOPO:levulinic acid system $\left(\chi_{\text {TOPO }}=0.00-1.00\right)$ were plotted in Figure 6 , with the corresponding onset temperatures for mass loss $\left(T_{\mathrm{d}}\right)$ and second $\left(T_{2}\right)$ stage of thermal decomposition, listed in Table 3 and plotted in Figure 7. Most mixtures decomposed in a two-step process, in analogy to TOPO:malonic acid, with the exception of two compositions ( $\chi_{\text {TOPO }}=0.33$ and 0.40 ), which decomposed in three steps (Figure 7), featuring an additional, intermediate decomposition step $\left(T_{3}\right)$. Examples of TGA and DTG plots corresponding to the three-step decomposition (Figure 8, top and Figure S28 SI) and two-step decomposition (Figure 8, bottom and Figure $\mathrm{S} 27 \mathrm{SI}$ ) are deposited in this paper and in SI. Furthermore, whereas decomposition steps of TOPO:malonic acid mixtures were clearly defined, for TOPO:levulinic acid mixtures there was much overlap between the steps (Figure S18 vs. Figure 8 and Figures S27-28 SI). Even reducing the heating rate to $1{ }^{\circ} \mathrm{C} \mathrm{min}^{-1}$ (Figure S29 SI) lead to no appreciable improvement in resolution of thermograms recorded for TOPO:malonic acid mixtures.

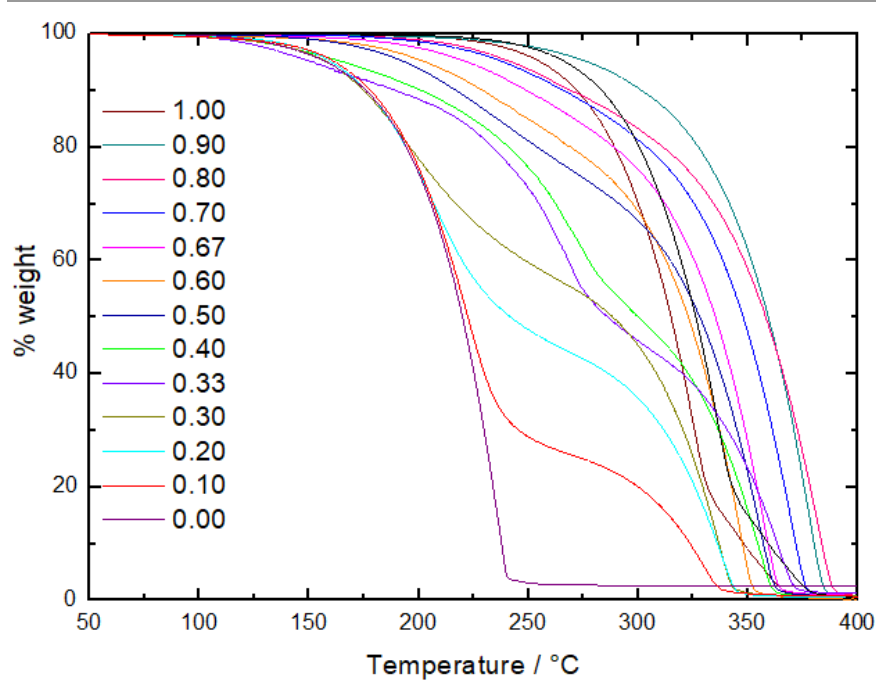

Figure 6. Mass loss profile of TOPO:levulinic acid mixtures under TGA dynamic heating regime $\left(10^{\circ} \mathrm{C} \mathrm{min}^{-1}\right)$ 
The onset of mass loss, corresponding to decomposition of neat levulinic acid, was recorded at $T_{\mathrm{d}}=106.5^{\circ} \mathrm{C}$ (to the authors' surprise, no literature comparison was available). In mixtures with low TOPO content (up to $\chi_{\text {TOPO }}=0.30$ ), $T_{\mathrm{d}}$ values remained similar to that of the neat acid. The $\chi_{\text {TOPO }}=0.33$ composition exhibited the lowest thermal stability $\left(91.7^{\circ} \mathrm{C}\right)$, in analogy with the behaviour observed in the TOPO:malonic acid system (Table 2 vs. Table 3). However, further increase in $\chi_{\text {Topo }}$ resulted in a steady growth of $T_{\mathrm{d}}$ values, several decades above the $T_{\mathrm{d}}$ value of neat levulinic acid (Figure 7).

Table 3. Onset of thermal decomposition $\left(T_{\mathrm{d}}\right)$ for TOPO:levulinic acid mixtures across whole compositional range

\begin{tabular}{cccc}
\hline$\chi_{\text {TOPO }}$ & $\boldsymbol{T}_{\mathrm{d}}$ (onset) $/{ }^{\circ} \mathbf{C}$ & $\boldsymbol{T}_{\mathbf{2}} /{ }^{\circ} \mathbf{C}$ & $\boldsymbol{T}_{\mathbf{3}} /{ }^{\circ} \mathbf{C}$ \\
\hline 1.00 & 204 & - & - \\
0.90 & 198 & 303 & - \\
0.80 & 181 & 273 & - \\
0.70 & 169 & 279 & - \\
0.67 & 155 & 273 & - \\
0.60 & 141 & 276 & - \\
0.50 & 130 & 276 & - \\
0.40 & 108 & 304 & 198 \\
0.33 & 92 & 308 & 179 \\
0.30 & 102 & 272 & - \\
0.20 & 106 & 276 & - \\
0.10 & 106 & 273 & - \\
0.00 & 107 & - & - \\
\hline
\end{tabular}

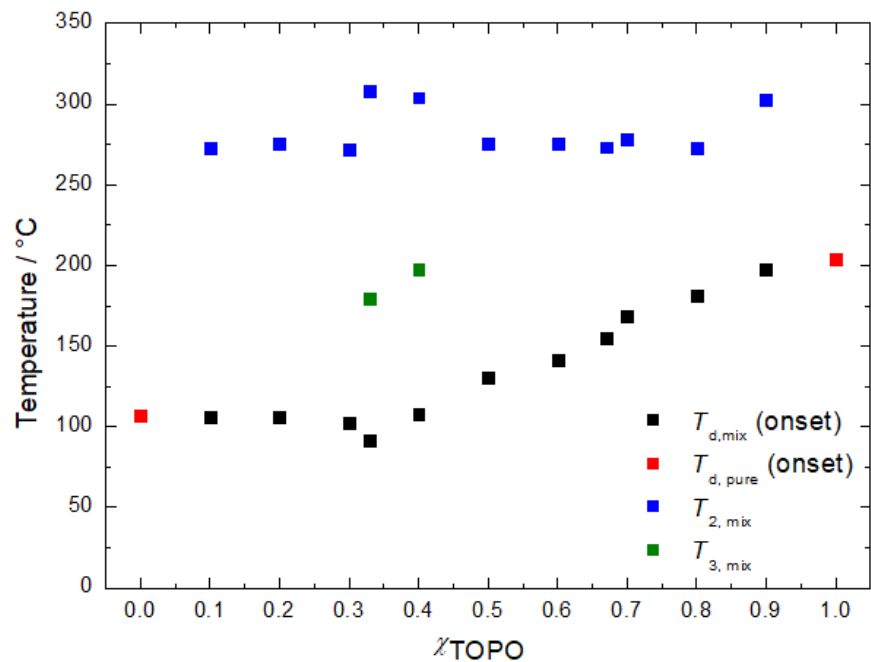

Figure 7. Onset of mass loss in thermal decomposition stages one (black squares) and two (blue squares) and three (green squares) in TOPO:levulinic acid mixtures and neat components (red squares). Described as thermal decomposition ( $T_{\mathrm{d}}$ onset) and onset of mass loss in the second $\left(T_{2}\right)$ and third $\left(T_{3}\right)$ step as a function of TOPO mole ratio under TGA dynamic heating at $10^{\circ} \mathrm{C} \mathrm{min}-1$

For neat levulinic acid and for mixtures with low TOPO loadings $\left(\chi_{\text {TOPO }}=0.00\right.$ to 0.30 ) the onset of decomposition was consistently slightly above $100{ }^{\circ} \mathrm{C}$, pointing to dehydration of levulinic acid. Loss of $\mathrm{H}_{2} \mathrm{O}$ is consistent with formation of furanones (3,4-dihydro-6-methyl-2H-pyran-2-one) by water elimination from the enol form of levulinic acid keto-enol equilibrium (Eq. 6). ${ }^{86}$ The presence of TOPO is associated with the second stage of decomposition (see Figure 7 and an example of DSC/DTG plot in Figure 8, bottom).<smiles>C#CC(O)=CCC(=O)OCCO</smiles>

Eq. 6.

A marked change in thermal decomposition pattern appears at $\chi_{\text {TOPO }}=0.33$, for which there is one mole of TOPO per two moles of carboxylic acid functionality present (and TOPO has been reported to preferentially interact with two hydrogen bond donors). ${ }^{87}$ The TGA/DTG plots for $\chi_{\text {TOPO }}=0.33$ and 0.40 are very complex, with three groups of thermal events (Figure 8 , top, Figure $\mathrm{S} 28 \mathrm{SI}$ ). Onsets of these events are plotted in Figure 7. For both compositions, the first step appears to be related to water loss, and the last - to thermal decomposition of TOPO, with a slightly higher onset of $T_{2}$ resulting from overlap with $T_{3}$. The middle event $\left(T_{3}\right)$ is represented by a composite peak in the DTG curve, with two well-visible maxima and a shoulder. It is difficult to speculate what each of these features represents, but it can be assumed that they are related to loss/decomposition of levulinic acid from the sample.

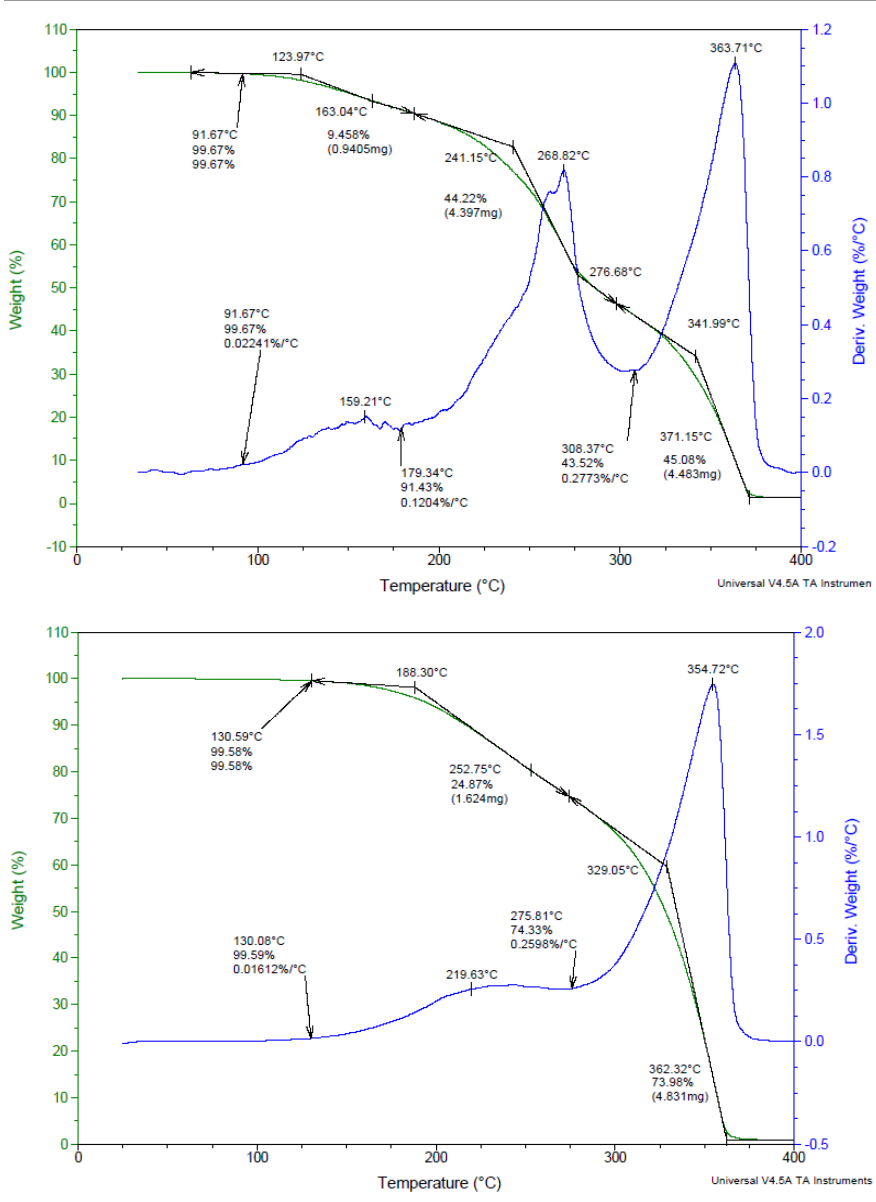

Figure 8. TGA traces for TOPO:levulinic acid mixtures under dynamic heating at $10{ }^{\circ} \mathrm{C} \mathrm{min}-1$ from room temperature to $400{ }^{\circ} \mathrm{C}$. The onset of each thermal event is depicted by arrows on the DTG plot (blue line). Top: $\chi_{\text {TOPO }}=0.33$ showing 3-stage mass loss $-T_{1}=92^{\circ} \mathrm{C}, T_{2}=308^{\circ} \mathrm{C}, T_{3}=179^{\circ} \mathrm{C}$. Bottom: $\chi_{\text {Topo }}=0.50$ showing 2-stage mass loss $-T_{1}=130^{\circ} \mathrm{C}, T_{2}=276^{\circ} \mathrm{C}$ 
Finally, compositions with high TOPO content $\left(\chi_{\text {TOPO }}=0.50\right.$ to 0.90$)$, are again characterised by a two-step decomposition (Figure 8, bottom). The water loss feature is absent, and the first thermal event $\left(T_{\mathrm{d}}\right)$ appears to be at the same temperature range as the shoulder in the middle event of the DTG plot for $\chi_{\text {TOPO }}=0.33$ (Figure 8 , top). These mixtures are more stable than neat levulinic acid (Figure 7) which can be rationalised by strong hydrogen-bonding with TOPO suppressing decomposition via water elimination. The first step of thermal decomposition was understood to arise from sublimation and evaporation/decomposition of levulinic acid, followed by thermal decomposition of TOPO.

Again, further study was focussed on the least stable composition, $\chi_{\text {TOPO }}=0.33$, which also displayed the most complex behaviour. Isothermal TGA study of the $\chi_{\text {TOPO }}=0.33$ sample at $90{ }^{\circ} \mathrm{C}$ (Figure 9) revealed a lower rate of mass loss than for the analogous composition of TOPO:malonic acid (see comparison in Figure S34 SI).

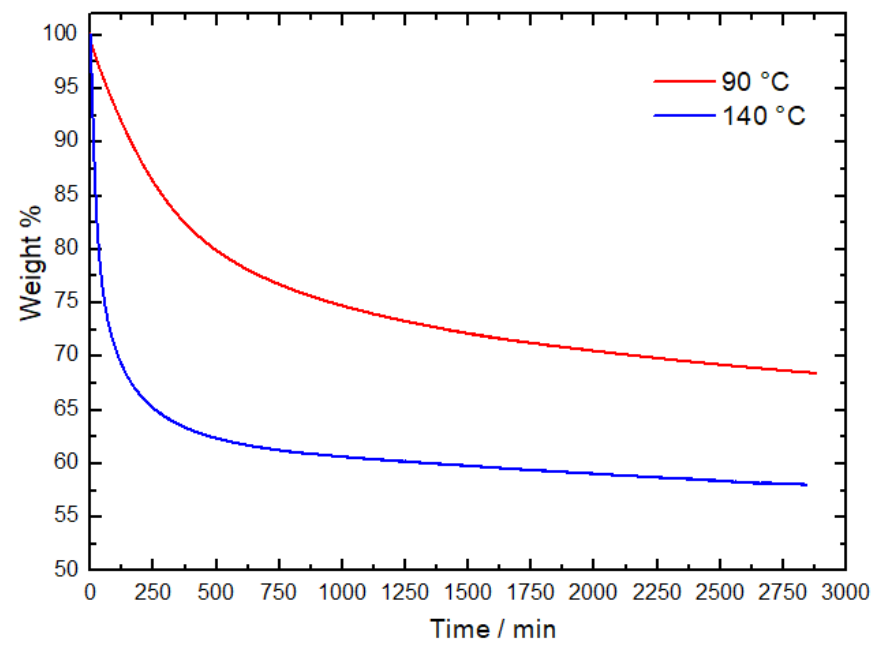

Figure 9. Mass loss profile of separate $\chi_{\text {TOPO }}=0.33$ TOPO:levulinic acid mixtures isothermal at $90^{\circ} \mathrm{C}$ and $140{ }^{\circ} \mathrm{C}$. Initial heating rate $50^{\circ} \mathrm{C} \mathrm{min}^{-1}$

At $90{ }^{\circ} \mathrm{C}$, about $20 \%$ of sample was lost after $500 \mathrm{~min}$. The $20 \%$ loss accounts for more than dehydration ( $6 \%$ of sample) but does not reach mass loss of levulinic acid (38\%), even after 2 days (2800 $\mathrm{min}$ ). The mass loss rate was not constant, but decreased steadily, from initial $4.0 \% \mathrm{~h}^{-1}$ to $2.6 \% \mathrm{~h}^{-1}$ after $2 \mathrm{~h}$, and further decreased afterwards. This was contrasting with steady loss of $5.8 \% \mathrm{~h}^{-1}$ over the first $3 \mathrm{~h}$ for the corresponding TOPO:malonic acid mixture, leading to loss of the entire acid component. However, in the case of TOPO:levulinic acid, the continuous decrease in weight \% (Figure 9) suggests that a major route of mass loss is levulinic acid evaporation towards a liquid composition with a very low vapour pressure. The same experiment was repeated at $140{ }^{\circ} \mathrm{C}$ (Figure 9, Figures S31-33 SI), which led to mass loss of $c a .38 \%$ after $500 \mathrm{~min}$, corresponding to removal of the levulinic acid component from the sample, and much lower mass loss rate afterwards.

Based on the isothermal TGA studies, the large-scale experiments were carried out at 125 and $140{ }^{\circ} \mathrm{C}$, in order to reach appreciable rate of thermal decomposition. In each case, a sample was heated in a round-bottomed flask ( $1 \mathrm{~h}$, under the flow of argon), which resulted in the sublimation/evaporation of large quantities of a white solid that deposited as crystals around the neck of the flask (Figure 10). This was identified as levulinic acid by ${ }^{13} \mathrm{C}$ NMR spectroscopy (Figure S45 SI). Meanwhile, the liquid changed its appearance from colourless to yellow. The evolved gas analysis by in situ GC-MS indicated the loss of $\mathrm{H}_{2} \mathrm{O}$ and $\mathrm{CO}_{2}$, with the loss of $\mathrm{H}_{2} \mathrm{O}$ increased significantly with increasing temperature from 125 to $140{ }^{\circ} \mathrm{C}$ (Figures S34-S35 SI).

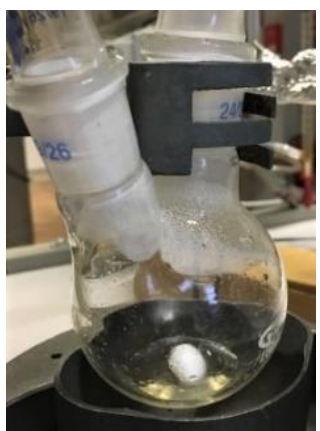

Figure 10. Sublimation/evaporation of levulinic acid from the $\chi_{\text {TOPO }}=0.33$ TOPO:levulinic acid mixture, heated at $140{ }^{\circ} \mathrm{C}$, under argon flow, $60 \mathrm{~min}$

The complicated appearance of the TGA/DTG thermogram (Figure 8, top) can be justified by three processes occurring in parallel: sublimation/evaporation of levulinic acid, dehydration (Eq. 6) and decarboxylation to butanone (Eq. 7). ${ }^{88,89}$

$$
\mathrm{CH}_{3} \mathrm{C}(\mathrm{O})\left(\mathrm{CH}_{2}\right)_{2} \mathrm{COOH} \rightarrow \mathrm{CH}_{3} \mathrm{C}(\mathrm{O}) \mathrm{CH}_{2} \mathrm{CH}_{3}+\mathrm{CO}_{2} \quad \text { Eq. } 7 .
$$

${ }^{1} \mathrm{H}$ NMR spectra of the post-thermolysis liquid (Figure S41 vs S43 SI) showed a reduction in the relative ratio of levulinic acid to TOPO, when compared to the starting composition, but no decomposition products were identified. This can be justified by the tendency for further rapid decomposition of 3,4-dihydro-6methyl-2H-pyran-2-one, and immediate evaporation of butanone (boiling point of $\left.80^{\circ} \mathrm{C}\right) .88$

Comparison of thermal stability in both systems. Concluding the thermal stability study, it is demonstrated that thermal stability of eutectics or similar mixtures must be carefully studied on case-by-case basis, and no allencompassing conclusions should be drawn. Whereas TOPO:malonic acid mixtures had lower thermal stability than the neat acid, likely owing to a self-catalysing effect, TOPO:levulinic acid liquids ( $\chi_{\text {TOPO }}=0.50$ to 0.90 ) were significantly more stable than neat levulinic acid; preventing decomposition by dehydration. Similarly, with increasing TOPO content and the resulting likely elevation of the mixture boiling point, this would lead to a lower vapour pressure and smaller mass loss due to evaporation. Comparisons of thermal decomposition onset of TOPO:malonic acid and TOPO:levulinic acid mixtures are presented in SI (Figure S47 SI).

\section{Phase behaviour}

Phase diagrams for the TOPO:malonic acid and TOPO:levulinic acid mixtures were constructed using the combination of 
differential scanning calorimetry (DSC) (Figures S47-70 SI) and visual observation of samples in a solid-liquid cell (SLC). Temperature $\left(T_{f}\right)$ and enthalpy of fusion $\left(\Delta H_{f}\right)$ data for pure components are summarised in Table S15 SI.

Ideal liquidus phase boundaries were approximated (assuming activity coefficients $\gamma_{i}=1$ ) using Eq. 8, where $\chi_{i}$ is the mole ratio of component $i, \gamma_{i}$ is the activity co-efficient of component $i$ at a given mole ratio, $\Delta H_{\mathrm{f}}$ is the enthalpy of fusion of the neat components, $R$ is the universal gas constant (8.314 J $\left.\mathrm{mol}^{-1} \mathrm{~K}^{-1}\right), T_{\mathrm{f}}$ is the temperature of fusion of neat components (in $\mathrm{K}$ ) and $T$ is the temperature (in $\mathrm{K}$ ). The specific heat capacity term was assumed to have an insignificant impact on ideal liquidus phase boundary calculations $\left(\Delta_{\mathrm{f}} C_{p}=0\right)$, which is true for mixtures in which neat components have similar melting points. ${ }^{1,90,91}$

$$
\ln \left(\chi_{i} \gamma_{i}\right)=\frac{\Delta H_{f}}{R}\left(\frac{1}{T_{f}}-\frac{1}{T}\right) \quad \text { Eq. } 8 .
$$

TOPO:malonic acid. TOPO:malonic acid mixtures formed homogeneous room temperature liquids between $\chi_{\text {TOPO }}=0.55$ and 0.67. Mixtures with lower TOPO loading $\left(\chi_{\text {TOPO }}=0.10-0.50\right)$ were heterogenous at room temperature, containing both solid and liquid components, the proportion of the liquid component increasing with increasing $\chi_{\text {TOPO }}\left(\chi_{\text {TOPO }}=0.10\right.$ appeared solid $)$. Furthermore, the $\chi_{\text {TOPO }}=0.70$ composition was biphasic (solid with a small quantity of liquid) and gradually solidified over the course of 2 weeks. All $\chi_{\text {TOPO }}>0.70$ samples appeared solid at room temperature.

The phase diagram for TOPO:malonic acid was constructed using both DSC and SLC results and is shown in Figure 9. DSC scans were recorded over the range -90 to $70^{\circ} \mathrm{C}$ and maxima of all first-order endothermic phase transitions (melting events) were recorded. However, some thermal events were close to (or above) the onset of thermal decomposition temperature $\left(T_{\mathrm{d}}\right)$ of the corresponding samples, therefore not accessible through DSC. SCL experiments could be carried out above $T_{\mathrm{d}}$ without concern about damage to the apparatus; however, it should be noted that $\chi_{\text {TOPO }}=0.00-0.33$ samples turned yellow upon melting. The respective observed transition temperatures are shown in Table 4.

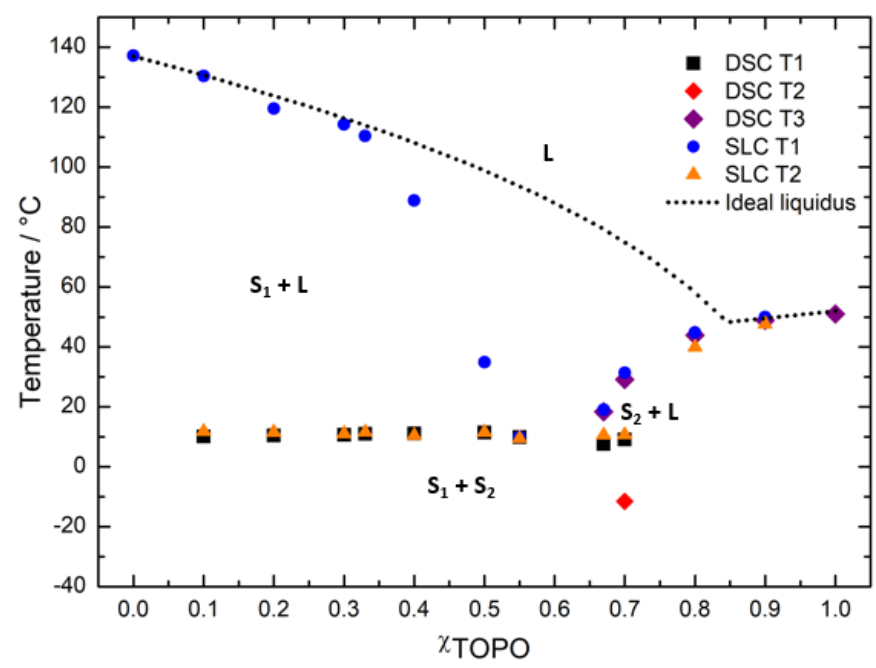

Figure 9. Phase diagram for TOPO:malonic acid mixtures across the whole compositional range. Constructed from SLC and DSC results. $S=$ solid, $L=$ liquid

The phase diagram for TOPO:malonic acid shows characteristic simple eutectic behaviour of the mixtures classified by Nývlt as one in which components do not form a compound and are miscible and immiscible in the liquid and solid phases, respectively. ${ }^{92}$ In the region $\chi_{\text {TOPO }}<0.60$, the phase behaviour is uncomplicated. Endothermic peaks associated with the melting point of the eutectic composition (ca. $11^{\circ} \mathrm{C}$ ) are evident from DSC (DSC $T_{1}$ ) and are in very good agreement with the onset of stirring bar movement in SLC (SLC $T_{2}$ ). Furthermore, the liquidus point observed using the solidliquid cell (SLC $T_{1}$ ) corresponds to melting of excess malonic acid.

On the TOPO-rich side of the phase diagram, $\chi_{\text {TOPO }}>0.70$, data recorded as DSC $T_{3}$, SLC $T_{1}$ and SLC $T_{2}$ all trace the melting point of samples that are solid at room temperature, and all melt to give clear liquids at, or below, $50{ }^{\circ} \mathrm{C}$. There was no evidence of eutectic melting at $\chi_{\text {TOPO }}>0.70$. However, 'wet patches' were found in a $\chi_{\text {TOPO }}=0.80$ sample left at $30{ }^{\circ} \mathrm{C}$ overnight, suggesting that the dissolution of TOPO is very slow in samples at $\chi_{\text {TOPO }}>0.70$.

Compositions $\chi_{\text {TOPO }}=0.67$ and 0.70 displayed more complex phase behaviour. For example, the DSC scan for $\chi_{\text {TOPO }}=0.67$ (Figure S57) features two first-order, endothermic phase transitions, accompanied by a broad, two-stage coldcrystallisation and an additional crystallisation upon cooling.

At $\chi_{\text {TOPO }}=0.70$ there is a low temperature transitions noted as DSC $T_{2}$, however, it is likely that this is a solid-solid transition. Again, onset of stirring bar movement in SLC (SLC $T_{2}$ ) and DSC $T_{1}$ are aligned and correspond to the melting of the eutectic composition. The highest-temperature feature in the DSC measurements (DSC $T_{3}$ ) aligns with the observed liquidus points (SLC $T_{1}$ ) and corresponds to the melting of TOPO in the mixtures.

Finally, the $\chi_{\text {TOPO }}=0.55$ sample exhibited one first order transition in the DSC trace which lies along the line corresponding to the observed eutectic isotherm line and the $\chi_{\text {TOPO }}=0.60$ sample is the only composition that does not feature a first-order transition in a DSC scan. Rather, there was a glass softening observed in the SLC, reported as the onset of 
stirrer bar movement, SLC $T_{\mathrm{g}}\left(-4.0^{\circ} \mathrm{C}\right)$, with inhibited crystallisation resulting from the mixture heterogeneity. This increases the extent of disruption and frustration of packing of species within a single crystalline lattice. TOPO:dodecanoic acid mixtures have been reported by the Kroon group whereby the eutectic point lies at $\chi_{\text {TOPO }}=0.43 .{ }^{47}$

It is expected that below the horizontal solidus line (ca. $11^{\circ} \mathrm{C}$ ) corresponding to the observed eutectic isotherm, the samples are heterogenous solids. Above the highest melting points plotted, an unsaturated, homogenous solution exists and between these lines saturated solutions co-exist with crystals of neat components. There was no evidence of a melting at $c a$. $11^{\circ} \mathrm{C}$ in samples above $\chi_{\text {TOPO }}=0.70$ using $\mathrm{DSC}$ and SLC apparatus, however, it is likely that kinetic effects hamper the detection of the eutectic composition in these samples.

Table 4. Data used to construct TOPO:malonic acid phase diagram

\begin{tabular}{cccc|ccc}
\multirow{2}{*}{$\chi_{\text {TOPO }}$} & \multicolumn{6}{c}{ Phase change temperature $/{ }^{\circ} \mathbf{C}$} \\
\cline { 2 - 7 } & \multicolumn{7}{c}{ DSC } & & \multicolumn{3}{c}{ SLC } & \\
\cline { 2 - 7 } & $T_{1}$ & $T_{2}$ & $T_{3}$ & $T_{1}$ & $T_{2}$ & $T_{\mathbf{g}}$ \\
\hline 0.00 & - & - & - & 137 & - & - \\
0.10 & 10 & - & - & 130 & 12 & - \\
0.20 & 10 & - & - & 120 & 12 & - \\
0.30 & 11 & - & - & 114 & 11 & - \\
0.33 & 11 & - & - & 110 & 12 & - \\
0.40 & 11 & - & - & 89 & 11 & - \\
0.50 & 11 & - & - & 35 & 12 & - \\
0.55 & 10 & - & - & 10 & 10 & - \\
0.60 & - & - & - & - & - & -4 \\
0.67 & 8 & - & 18 & 19 & 11 & - \\
0.70 & 9 & -12 & 29 & 31 & 11 & - \\
0.80 & - & - & 44 & 45 & 40 & - \\
0.90 & - & - & 49 & 50 & 48 & - \\
1.00 & - & - & 52 & 52 & - & - \\
\end{tabular}

TOPO:levulinic acid. The phase diagram for TOPO:levulinic acid (Figure 12 and Table 5) acid differs from that for TOPO:malonic acid, arguably because levulinic acid has only one carboxylic acid group and there is a large difference in melting points of the pure malonic acid and levulinic acid components (137.2 and $32.2^{\circ} \mathrm{C}$, respectively). These mixtures exhibit characteristic eutectic profiles with the lowest temperature melting point in the region around $\chi_{\text {TOPO }}=0.40$. This is consistent with other TOPO mixtures: with phenol ${ }^{48}$ and dodecanoic acid. ${ }^{47}$

At room temperature, samples within the $\chi_{\text {TOPO }}=0.10-0.20$ composition region were biphasic, containing mostly liquid with small quantity of suspended solid. The corresponding part of the phase diagram (Figure 12) features the liquidus line slightly above ambient temperature (as recorded from solid-liquid cell, SLC $T_{1}$ and SLC $T_{2}$ ), corresponding to melting of excess levulinic acid. From the DSC data, a phase transition at/slightly below ambient temperature (DSC $T_{1}$ ) corresponds to a melting event. In addition, DSC revealed a low-temperature endothermic event at $c a .-20^{\circ} \mathrm{C}$ (DSC $T_{2}$ ), possibly indicating the transition between heterogeneous conjugated solid phases of TOPO and levulinic acid and a levulinic acid solid solution with TOPO acting as the solute in a levulinic acid matrix ' $\mathrm{S} \alpha$ '.
Compositions $\chi_{\text {TOPO }}=0.30-0.50$ were homogenous liquids at ambient temperature. Finally, DSC scans for $\chi_{\text {TOPO }}=0.30-0.40$ compositions featured low-enthalpy first-order events (Figures S64-S66 in SI).

On the TOPO-rich side of the phase diagram, the $\chi_{\text {TOPO }}=0.50$ mixture forms a liquid at room temperature whereas increasing $\chi_{\text {TOPO }}$ to 0.60 generated a gel with liquid entrapped within a solid matrix. At $\chi_{\text {TOPO }}>0.67$, the mixtures formed solids under ambient conditions. In the phase diagram, for $\chi_{\text {TOPO }}>0.50$, data recorded as DSC $T_{1}, \operatorname{SLC} T_{1}$ and SLC $T_{2}$ trace the melting point of samples that melted in a single event to give clear liquids. The liquidus point was below ambient for the $\chi_{\text {TOPO }}=0.50$ mixture, which aligns well with the preliminary visual observation. Furthermore, low enthalpy first order events in $\chi_{\text {TOPO }}=0.30-40$, a broad shoulder in $\chi_{\text {TOPO }}=0.50-67$ compositions (DSC $T_{3}$ ), and SLC $T_{2}$ for $\chi_{\text {TOPO }}=0.50$, trace a line corresponding to a eutectic isotherm that melts around $c a .-2{ }^{\circ} \mathrm{C}$.

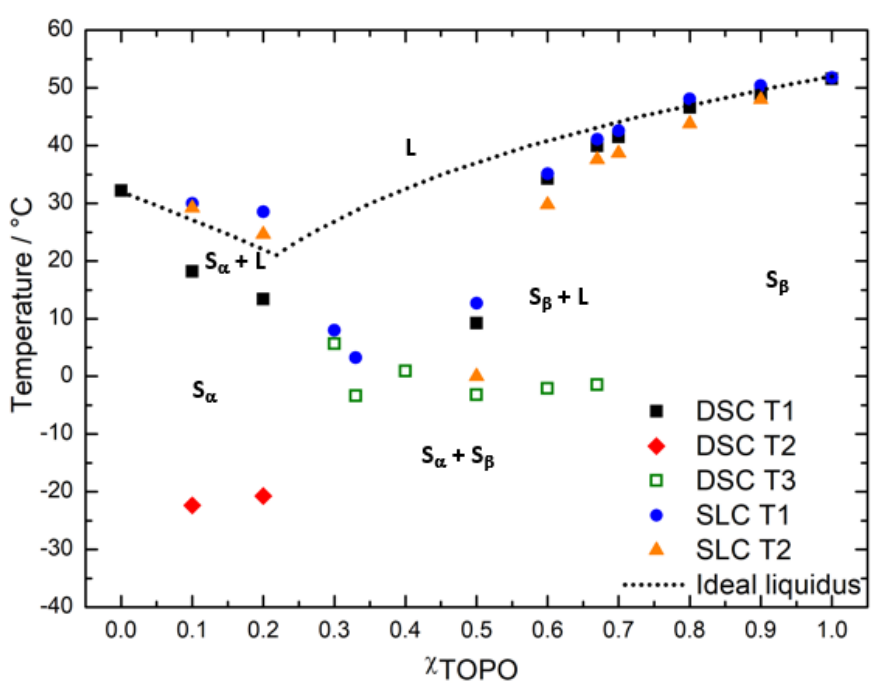

Figure 12. Phase diagram for TOPO:levulinic acid mixtures across the whole compositional range. Constructed from SLC and DSC results. $S=$ solid, $L=$ liquid

It is thought that the TOPO:levulinic acid phase diagram is of type 2-IIla, following the binary system classification by Nývlt. ${ }^{92}$ The pure components have close melting points $\left(\chi_{\text {TOPO }}=0.00\right.$ vs. 1.00 melt at 32 and $51{ }^{\circ} \mathrm{C}$, respectively) and partial miscibility in the solid phase Therefore, below the horizontal solidus line $\left(c a .-2{ }^{\circ} \mathrm{C}\right)$ corresponding to the observed eutectic isotherm, the samples are heterogenous conjugated solids. Regions identified as ' $\mathrm{S}_{\alpha}$ ' and ' $\mathrm{S}_{\beta}$ ' correspond to levulinic acid and TOPO solid solutions respectively whereby there is partial miscibility between components as a solute of one component within a matrix of the other. Above the highest melting points plotted, an unsaturated, homogenous TOPO:levulinic acid solution exists and between the lines representing homogenous unsaturated solutions and solid solutions lie saturated solutions which co-exist heterogeneously with levulinic acid ' $\mathrm{S}_{\alpha}$ ' and TOPO ' $\mathrm{S}_{\beta}$ ' solid solutions.

Discontinuous solid solutions of this type are common in binary phase diagrams of fatty mixtures ${ }^{93}$ and result from structural differences between components. ${ }^{94}$ 
Table 5. Data used to construct TOPO:levulinic acid phase diagram

\begin{tabular}{|c|c|c|c|c|c|c|}
\hline \multirow[t]{3}{*}{$\chi_{\text {TOPO }}$} & \multicolumn{6}{|c|}{ Phase change temperature $/{ }^{\circ} \mathrm{C}$} \\
\hline & \multicolumn{3}{|c|}{ DSC } & \multicolumn{3}{|c|}{ SLC } \\
\hline & $T_{1}$ & $T_{2}$ & $T_{3}$ & $T_{1}$ & $T_{2}$ & $T_{\mathrm{g}}$ \\
\hline 0.00 & 32 & - & - & - & - & - \\
\hline 0.10 & 18 & -22 & - & 30 & 29 & - \\
\hline 0.20 & 13 & -21 & - & 29 & 25 & - \\
\hline 0.30 & - & - & 6 & 8 & - & -14 \\
\hline 0.33 & - & - & -3 & 3 & - & -24 \\
\hline 0.40 & - & - & 1 & - & - & -36 \\
\hline 0.50 & 9 & - & -3 & 13 & 0.0 & - \\
\hline 0.60 & 34 & - & -2 & 35 & 30 & - \\
\hline 0.67 & 40 & - & -2 & 41 & 38 & - \\
\hline 0.70 & 42 & - & - & 43 & 39 & - \\
\hline 0.80 & 47 & - & - & 48 & 44 & - \\
\hline 0.90 & 49 & - & - & 50 & 48 & - \\
\hline 1.00 & 52 & - & - & 52 & - & - \\
\hline
\end{tabular}

\section{P NMR spectroscopy}

TOPO:acid mixtures that were liquid at ambient temperature were studied neat using ${ }^{31} \mathrm{P}$ NMR spectroscopy to examine the strength of interactions of TOPO with the acids.

The ${ }^{31} \mathrm{P}$ chemical shift for free TOPO $\left(\chi_{\text {TOPO }}=1.00\right)$ varies with both solvent (for example, $\delta_{31 \mathrm{p}}=45.37 \mathrm{ppm}$ in $d_{6}$-acetone compared to $c a .46 \mathrm{ppm}$ in $d_{3}$-acetonitrile ${ }^{95}$ ) and concentration. This environmental response can be used as a measure of the degree of interaction with acids: in the presence of coordinating strong Lewis acids, the chemical shift can reach values around $\delta_{31 \mathrm{P}}=75-85 \mathrm{ppm}$ for liquid coordination complexes of $\mathrm{AlCl}_{3}$ and $\mathrm{GaCl}_{3}$ (which gives up to $\Delta \delta_{31 \mathrm{P}}=+36 \mathrm{ppm}$ of downfield shift). ${ }^{44}$ The body of relevant literature is even richer for triethylphosphine oxide (TEPO), which is used as the ${ }^{31} \mathrm{P}$ NMR probe of Lewis acidity ${ }^{96,97}$ and hydrogen bond strength. ${ }^{98}$

In this context, the liquid TOPO:malonic acid (Figure S73 SI) and TOPO:levulinic acid (Figure S74 SI) mixtures exhibit ${ }^{31} \mathrm{P}$ chemical shifts over the range $\delta_{31 \mathrm{P}}=53-57 \mathrm{ppm}\left(\Delta \delta_{31 \mathrm{P}}=\right.$ $+8-12 \mathrm{ppm}$ ), demonstrating strong hydrogen bonding. These results are very similar to work previously conducted by the group studying a TOPO:phenol system; ${ }^{48}$ as in our earlier work, there is $\Delta \delta_{31 \mathrm{P}}=1.6-2.0 \mathrm{ppm}$ downfield shift for each subsequent $\chi_{\text {TOPO }}=0.1$ increment, following a linear trend (Figure 13).

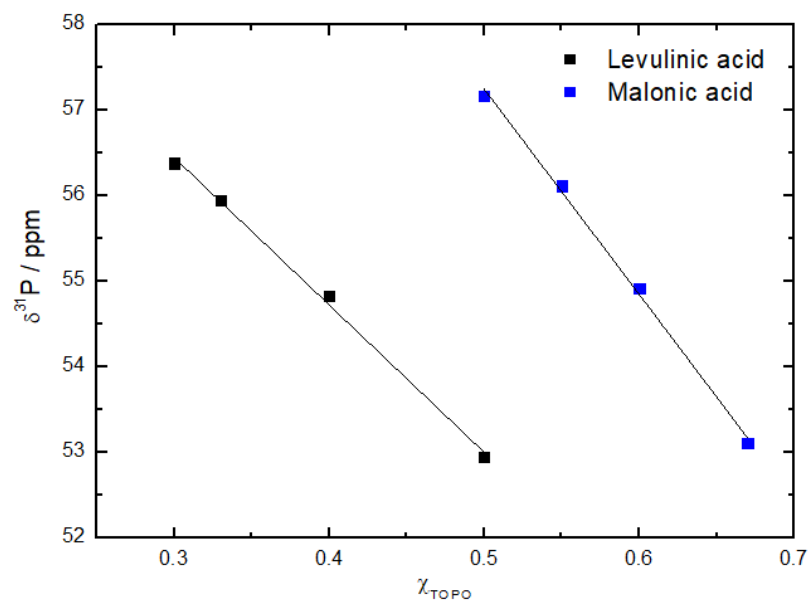

Figure 13. ${ }^{31 P}$ NMR chemical shifts as a function of $\chi_{\text {TOPO }}$ in TOPO:malonic acid and TOPO:levulinic acid liquid samples
When the magnitudes of the ${ }^{31} \mathrm{P}$ NMR chemical shifts recorded for different $\chi_{\text {TOPO }}$ values are compared in terms of hydrogen bonding motifs (Table 6), the shift in signal experiences in the presence of one, or two hydrogen-bonding carboxylic acid groups are remarkably similar and independent of the acids.

Table 6. ${ }^{31} \mathrm{P}$ chemical shifts associated with TOPO:malonic acid and TOPO:levulinic acid liquid samples. Neat, $\mathrm{D}_{3} \mathrm{PO}_{4}$ capillary, $25^{\circ} \mathrm{C}$

\begin{tabular}{ccccc}
\hline \multirow{2}{*}{ TOPO:acid unit } & \multicolumn{2}{c}{$\chi_{\text {TOPO }}$} & $\boldsymbol{\delta}^{\mathbf{3 1}} \mathbf{P} / \mathbf{p p m}$ & \multicolumn{2}{c}{$\chi_{\text {TOPO }}$} & $\boldsymbol{\delta}^{\mathbf{3 1}} \mathbf{P} / \mathbf{p p m}$ \\
\cline { 2 - 5 } & \multicolumn{2}{c}{ TOPO:malonic acid } & \multicolumn{2}{c}{ TOPO:levulinic acid } \\
\hline \multirow{2}{*}{$1: 2$} & 0.50 & 57.17 & 0.30 & 56.38 \\
& 0.55 & 56.12 & 0.33 & 55.95 \\
& 0.60 & 54.92 & & \\
$1: 1$ & 0.67 & 53.11 & 0.40 & 54.84 \\
& & & 0.50 & 52.95 \\
\hline
\end{tabular}

From this analysis, it can be inferred that the strength of interaction of carboxylic acids with TOPO depends chiefly on the ratio of carboxylic acid units to TOPO given that these acids all have largely similar $\mathrm{p} K_{\mathrm{a}}$ values. In the solid state, equimolar mixtures of triphenylphosphine oxide with benzoic acids exhibit one hydrogen bond per the phosphine oxide functionality. 99,100 However, it is also known that phosphine oxide $(P=O)$ moiety can exhibit an "ambidextrous" nature in hydrogen bonding in the solid state, whereby it can participate in more than one simultaneous hydrogen bond without compromising their strength in negative cooperativity. ${ }^{87}$ Furthermore, studies focusing on electron localisation function suggest that the phosphine oxide functionality has the potential to participate in up to three simultaneous hydrogen bonds in the solid state. ${ }^{87,101,102}$ It is thought that this ambidextrous nature should also characterise the liquid state. ${ }^{87}$

If this is interpreted in the context of partitioning of the acid between aqueous and TOPO-rich phase, this suggests that since all acids interact in similar manner at the $\mathrm{H}$-bonding site, a key difference to selectivity extraction and/or prevention of leaching is the hydrophobicity of the acid itself. This is in agreement with van den Bruinhorst et al. who showed that distribution coefficient of volatile fatty acids (VFAs) between a TOPO eutectic-aqueous phase followed butyric $>$ propionic $>$ acetic acid; indicating that extraction of these VFAs are based on extent of acid hydrophobicity. ${ }^{47}$

\section{Density}

Differential densities between the two phases is important for the ease of separations. Densities of TOPO:malonic acid and TOPO:levulinic acid liquid mixtures were recorded within the temperature range of $20-50{ }^{\circ} \mathrm{C}$, at $5{ }^{\circ} \mathrm{C}$ increments.

Densities and molar volumes of TOPO:malonic acid mixtures, plotted as a function of temperature (Figure 14 and tabulated in Table S16 and S17 SI), show density decrease and molar volume increase with increasing $\chi_{\text {TOPO }}$. This is expected, as TOPO is less dense than malonic acid $\left(\rho_{\text {TOPO }}=0.861 \mathrm{~g} \mathrm{~cm}^{-3}\right.$, $\left.\rho_{\mathrm{MA}}=1.62 \mathrm{~g} \mathrm{~cm}^{-3}\right)$. The density and molar volume of each liquid sample also decrease and increase linearly respectively with increasing temperature. 

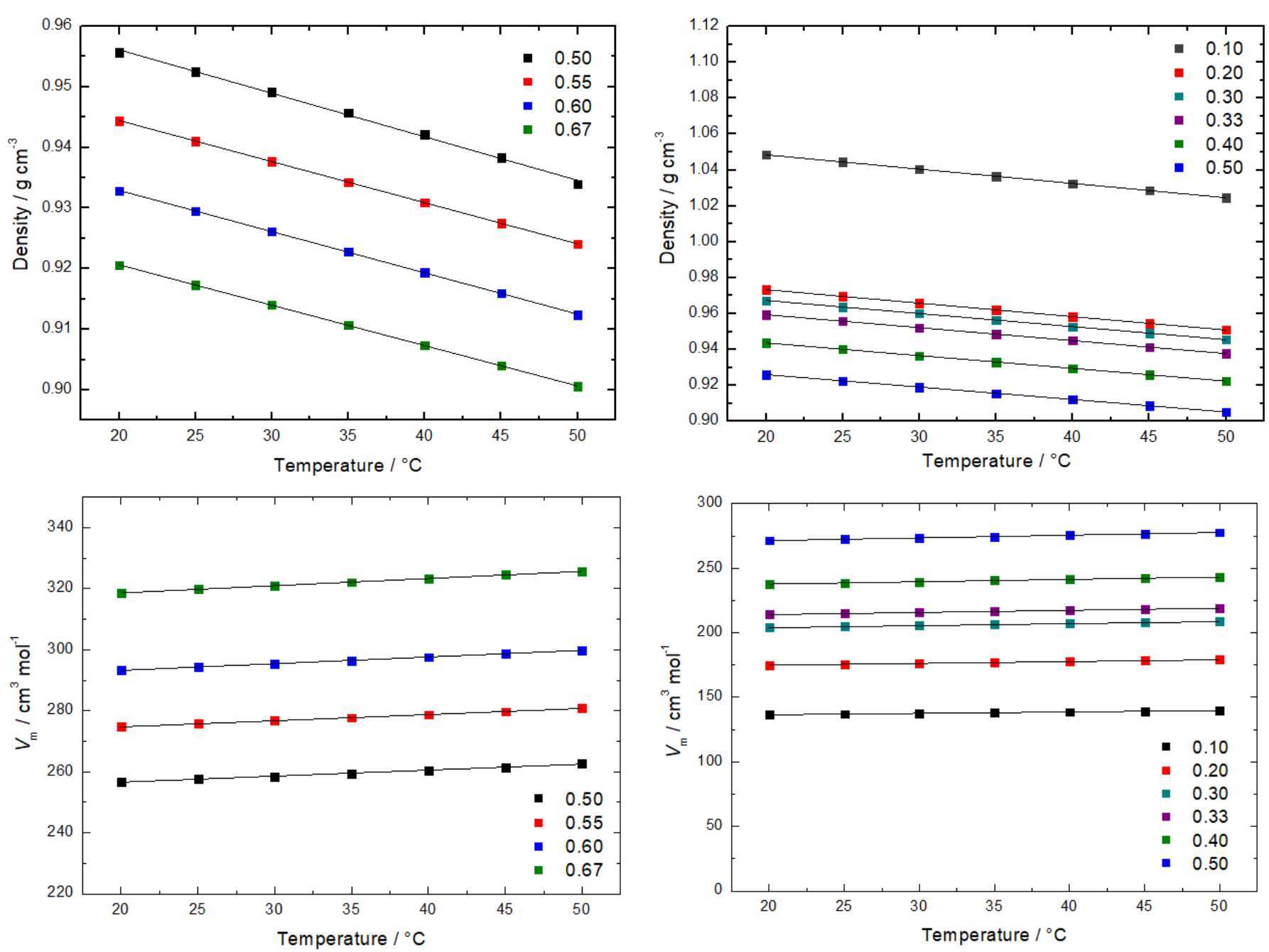

Figure 14. Top: Density of TOPO:malonic acid liquid mixtures as a function of temperature. Bottom: Molar volume $\left(V_{m}\right)$ of TOPO:malonic acid liquid mixtures as a function of temperature

Densities of TOPO:levulinic acid mixtures, plotted as a function of temperature (Figure 15 and tabulated in Table S16 and S17 SI) reveal a similar pattern, of density decrease and molar volume increase with increasing $\chi_{\text {TOPO }}$ value and with increasing temperature. However, the $\chi_{\text {TOPO }}=0.10$ sample is significantly more dense than the other systems; this is speculated to be due to the liquid structure of this sample being very similar to that of levulinic acid ( $\rho_{\text {levulinic acid }}=1.12738 \mathrm{~g} \mathrm{~cm}^{-3}$, $\left.35^{\circ} \mathrm{C}\right) .{ }^{103}$ Molar volumes in this case show that this as a result of the large molar mass difference between TOPO (386.63 $\left.\mathrm{g} \mathrm{mol}^{-1}\right)$ and levulinic acid $\left(116.12 \mathrm{~g} \mathrm{~mol}^{-1}\right)$ as expected.

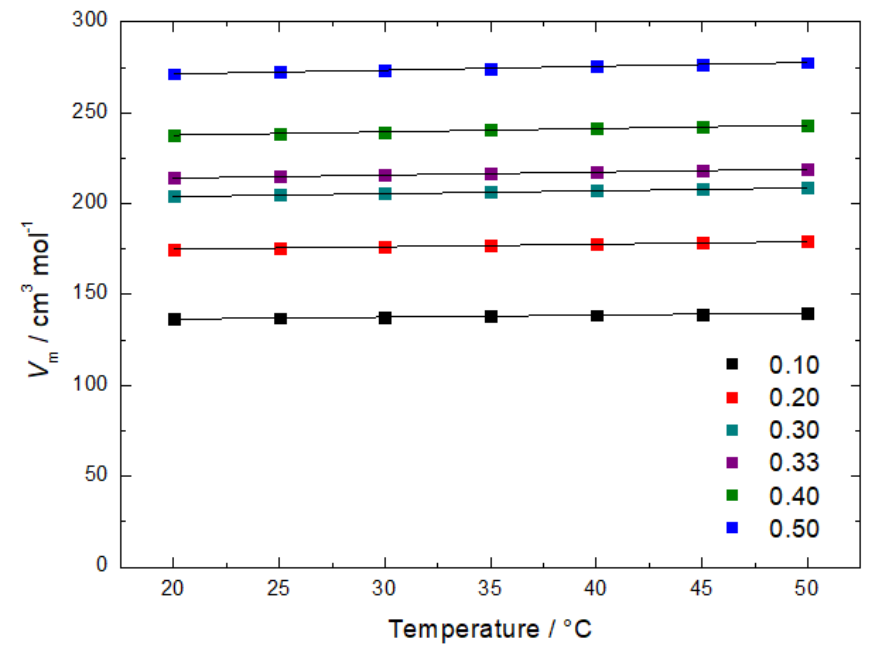

Figure 15. Top: Density of TOPO:levulinic acid liquid mixtures as a function of temperature. Bottom: Molar volume $\left(V_{\mathrm{m}}\right)$ of TOPO:levulinic acid liquid mixtures as a function of temperature

Data was plotted as a function of temperature and fitted to linear equations, $\rho=\mathrm{a}+\mathrm{b} T$ and $V_{\mathrm{m}}=\mathrm{a}+\mathrm{b} T$ where $\mathrm{a}$ is the $\mathrm{y}$ axis intercept, $\mathrm{b}$ is the gradient of the line, $\rho$ is density $\left(\mathrm{g} \mathrm{cm}^{-3}\right), V_{\mathrm{m}}$ is the molar volume $\left(\mathrm{cm}^{3} \mathrm{~mol}^{-1}\right)$ and $T$ is temperature $\left({ }^{\circ} \mathrm{C}\right)$. Equation parameters and absolute average deviation of the fits are plotted in Table 7 and Table S18 SI respectively. Residual plots can be found in Figures S75-S78 SI. A slightly better fit was achieved with a polynomial; however, we were hesitant to risk overinterpretation with this unusual fit to density/molar volume data, considering that the residuals are within the error of the measurement. 
Table 7. Fitting parameters from linear regression of the density and molar volume data for TOPO:malonic acid and TOPO:levulinic acid liquid mixtures as a function of temperature over the range $20-50{ }^{\circ} \mathrm{C}$. Units for a and $-\mathrm{b}$ for density data are $\mathrm{g} \mathrm{cm}^{-3}$ and $\mathrm{g} \mathrm{cm}^{-3}{ }^{\circ} \mathrm{C}^{-1}$ respectively and units for $\mathrm{a}$ and $\mathrm{b}$ for molar volume data are $\mathrm{cm}^{3} \mathrm{~mol}^{-1}$ and $\mathrm{cm}^{3} \mathrm{~mol}^{-1}{ }^{\circ} \mathrm{C}^{-1}$ respectively

\begin{tabular}{cccccc}
\hline \multirow{2}{*}{ Mixture } & \multirow{2}{*}{$\chi_{\text {TOPO }}$} & \multicolumn{2}{c}{ Density $(\rho)$} & \multicolumn{2}{c}{ Molar volume $\left(\boldsymbol{V}_{\mathrm{m}}\right)$} \\
\cline { 3 - 6 } & & $\mathbf{a}$ & $-\mathbf{b}$ & $\mathbf{a}$ & $\mathbf{b}$ \\
\hline TOPO:malonic acid & 0.50 & 0.9705 & 0.0007 & 252.6 & 0.1973 \\
& 0.55 & 0.9580 & 0.0007 & 270.7 & 0.2016 \\
& 0.60 & 0.9465 & 0.0007 & 288.9 & 0.2187 \\
& 0.67 & 0.9340 & 0.0007 & 313.9 & 0.2358 \\
\hline TOPO:levulinic acid & 0.10 & 1.0644 & 0.0008 & 134.4 & 0.1061 \\
& 0.20 & 0.9883 & 0.0007 & 172.1 & 0.1378 \\
& 0.30 & 0.9819 & 0.0007 & 200.8 & 0.1569 \\
& 0.33 & 0.9738 & 0.0007 & 210.8 & 0.1645 \\
& 0.40 & 0.9578 & 0.0007 & 234.0 & 0.1823 \\
& 0.50 & 0.9399 & 0.0007 & 267.3 & 0.2076 \\
\hline
\end{tabular}

Calculation of excess molar volumes $\left(V_{\mathrm{m}}^{\mathrm{E}}\right)$ would be beneficial to better understand interactions occurring in these liquids. However, as one or more neat components are solid at the temperature range studied, the inevitable volume expansion with liquification would obscure results resulting in positive $V_{m}$ values which are not representative of interactions occurring in the mixtures.

In conclusion, when extraction applications are concerned, compositions with lower acid loadings (high $\chi_{\text {TOPO }}$ values) lend themselves to be the best choice. They are characterised by the lowest density (potentially facilitating phase separation from the aqueous phase) and have a slightly stronger interaction between TOPO and acid, which may aid to limit leaching.

\section{Leaching study}

TOPO has very low solubility in water $\left(0.15 \mathrm{mg} \mathrm{L}^{-1}\right)^{104,105}$ and has been shown not to contaminate the aqueous phase when considering TOPO:phenol DES. ${ }^{48}$ In this work therefore, the studies on the aqueous stability of $\chi_{\text {TOPO }}=0.55$ and 0.67 TOPO:malonic acid mixtures focus on malonic acid leaching. The two compositions selected were at the opposite extremities of the liquid range. A summary of the leaching study results are shown in Table 8.

Table 8. Malonic acida leaching from eutectic phase into aqueous phase after contact. Equivolume org:aq, ambient temperature, shaking time: 20 mins. At $25^{\circ} \mathrm{C}: 107.8 \mathrm{~g} \mathrm{~L}^{-1}$ malonic acid in $\chi_{\text {TOPO }}=0.67$ TOPO:malonic acid and $150.2 \mathrm{~g} \mathrm{~L}^{-1}$ malonic acid in $\chi_{\text {TOPO }}=0.55$ TOPO:malonic acid

\begin{tabular}{|c|c|c|c|c|c|c|}
\hline \multirow[t]{2}{*}{$\begin{array}{c}{[\mathrm{HCl}] /} \\
\mathrm{M}\end{array}$} & \multirow[t]{2}{*}{$\chi_{\text {TOPO }}$} & \multicolumn{2}{|c|}{$\begin{array}{c}\text { [Malonic acid] }]_{\mathrm{aq}} \\
\qquad / \mathrm{g} \mathrm{L}^{-1}\end{array}$} & \multicolumn{3}{|c|}{$\begin{array}{c}\text { Mass loss at single contact / } \\
\% \text { Malonic acid }\end{array}$} \\
\hline & & FT-IR & TOC & FT-IR & TOC & Average \\
\hline \multirow[t]{2}{*}{0} & 0.67 & 15 & 14 & 14 & 13 & 14 \\
\hline & 0.55 & 59 & 56 & 39 & 37 & 38 \\
\hline \multirow[t]{2}{*}{6} & 0.67 & - & 50 & - & 46 & - \\
\hline & 0.55 & - & 92 & - & 61 & - \\
\hline
\end{tabular}

aMalonic acid solubility in $\mathrm{H}_{2} \mathrm{O}=763 \mathrm{~g} \mathrm{~L}^{-1}$ at $25^{\circ} \mathrm{C} .{ }^{106}$

Aligned with earlier observations for TOPO:phenol system, ${ }^{48}$ the hydrogen bond donor (i.e. malonic acid) was found to measurably leach from the TOPO:malonic acid mixture into the aqueous phase. The TOPO-rich composition used in gallium extraction $\left(\chi_{\text {TOPO }}=0.67\right)$ moderately leached malonic acid into deionised water (13-14\% of malonic acid mass was lost). Unfortuantely, this percentage rose significantly when the mixture was contacted with $6 \mathrm{M} \mathrm{HCl}(46 \%$ loss at the $\mathrm{HCl}$ acid concentration yielding optimum gallium extraction efficiency). In contrast to TOPO:phenol systems, leaching is highly sensitive to $\mathrm{pH}$ of the aqueous phase. The $\chi_{\text {TOPO }}=0.55$ mixture showed even greater propensity to leach malonic acid than the $\chi_{\text {TOPO }}=0.67$ mixture, resulting from the relative increase in initial malonic acid content: 150 vs $108 \mathrm{~g} \mathrm{~L}^{-1}$, respectively. This highlights the importance of designing extracting liquids with the highest mole ratio of TOPO possible, in order to limit the leaching of malonic acid.

As a result of this leaching, the composition of the organic TOPO:malonic acid eutectic mixture changed after contact with an aqueous phase (Table S19 SI). This compositional change is of particular interest when considering these TOPO:malonic acid eutectic mixtures as extractants. Taking the $\chi_{\text {TOPO }}=0.67$ mixture as an example and using a $6 \mathrm{M} \mathrm{HCl}$ aqueous phase due to its relevance in our test application, the TOPO mole ratio with respect to malonic acid is altered to $\chi_{\mathrm{TOPO}}=0.79$ (i.e. $\Delta \chi_{\mathrm{TOPO}}=$ 0.12). However, circling back to the TOPO:malonic acid phase diagram (Figure 11, Table 4) shows that, in contrast to what we observed, a $\chi_{\text {TOPO }}=0.79$ TOPO:malonic acid mixture would exhibit solid phase behaviour at this composition at ambient temperature (i.e. this compositional change would cross the solid-liquid phase boundary). Therefore, as the TOPO:malonic acid mixture remained in a liquid phase after pre-contact with 6 $\mathrm{M} \mathrm{HCl}$, this suggests that partial transfer of de-ionised water or aqueous $\mathrm{HCl}$ in the pre-contacting stage must occur in order to keep the organic phase liquified.

Despite leaching, malonic acid in aqueous streams does not raise the same level of concern as phenolic contaminated waste-water, as an environmentally benign and readily biodegradable compound. ${ }^{107}$ For an industrially-viable application, however, a longer-chain, more lipophilic analogue could be explored.

\section{Test application: liquid-liquid gallium extraction from aqueous acidic chloride feedstock using TOPO:malonic acid}

In order to demonstrate the potential for application of TOPO-based eutectics, the TOPO:malonic acid system was screened in a model extraction of gallium(III) from an aqueous feed. In general, gallium is extracted as a secondary element from acidic or basic waste streams, the former originating from zinc leach residue and LED waste and the latter from aluminium manufacturing waste (e.g. Bayer solutions or red mud). ${ }^{71,73,108}$ TOPO has been known to extract gallium from acidic chloride sources with dilution in a hydrocarbon diluent, the limiting factor being the solubility limit of TOPO. ${ }^{31,72,73}$ Concentrated, TOPO-rich liquids reported here appear to be the perfect solution to this problem. Furthermore, acetylacetone (acac) ${ }^{69}$ or various $\beta$-diketone ${ }^{70}$ functionalities have been reported to extract gallium from strongly basic aqueous sources, although 
their chemical instability in under basic conditions has prevented commercial use. ${ }^{71}$ In the acidic regime, however, carboxylic acids have been reported to extract gallium from dilute acidic chloride solutions. ${ }^{73,109,110}$ This, and the knowledge of gallium chloride forming liquid, hydrophobic adducts with TOPO, ${ }^{44}$ has led to the test use of a TOPO:malonic acid eutectic from acidic chloride aqueous feed, in the hope to reap a synergistic benefit of both components potentially involved in extraction.

As indicated earlier in this paper, the $\chi_{\text {TOPO }}=0.67$ composition appears to be the best choice of extractant, as being ambient-temperature liquid with high TOPO concentration, low density and strong affinity to the acid (for leakage prevention).

Extraction of gallium from acidic chloride aqueous phases was tested across a range of $\mathrm{HCl}$ concentrations, and compared to a standard benchmark $(0.004 \mathrm{M}$ TOPO in benzene, $6 \mathrm{M} \mathrm{HCl}$ containing $0.00568 \mathrm{M} \mathrm{GaCl}_{3}$ ) replicating conditions reported previously by Sato et al. ${ }^{31}$ Comparison of the results from this work and the benchmark is shown in Figure 16 (and tabulated in Table S20 SI).

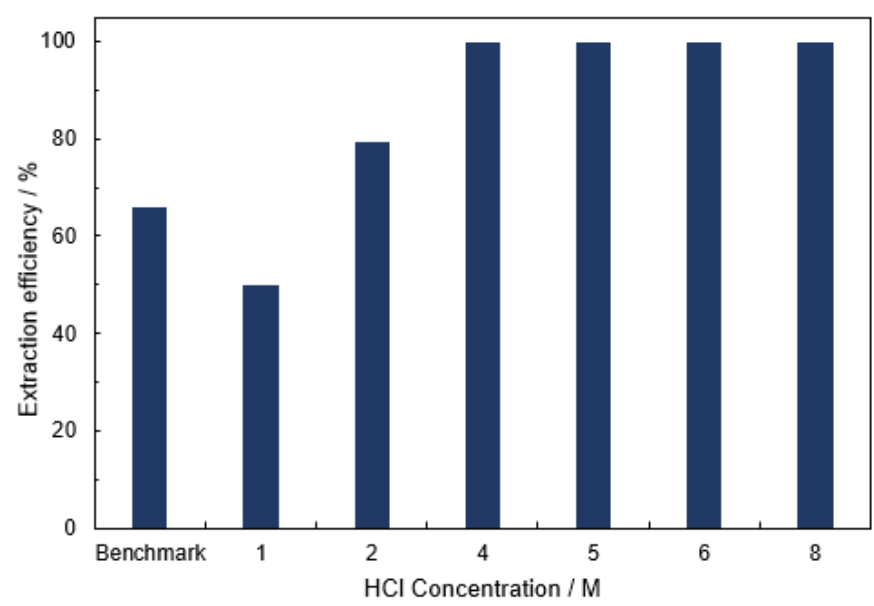

Figure 16. Extraction of gallium from aqueous acidic chloride feed across a range of $\mathrm{HC}$ concentrations from 1-8 M using $\chi_{\text {TOPO }}=0.67$ TOPO:malonic acid, compared to a benchmark extractant of $0.004 \mathrm{M}$ TOPO in benzene. Conditions: ambient temperature, initial $\mathrm{GaCl}_{3}$ concentration $=0.00568 \mathrm{M}$, org: aq 1:1, pre-contact time $10 \mathrm{~min}$, extraction time $10 \mathrm{~min}$

Extraction efficiency increases with increasing $\mathrm{HCl}$ concentration. This is due to the increased tendency to form $\left[\mathrm{GaCl}_{4}\right]^{-}$in the aqueous phase at higher $\mathrm{HCl}$ concentrations, ${ }^{111}$ whereas $\mathrm{GaCl}_{3}$ and/or products of hydrolysis (e.g. $\mathrm{Ga}(\mathrm{OH}) \mathrm{Cl}_{2}$ or $\mathrm{Ga}(\mathrm{OH})_{2} \mathrm{Cl}$ ) are the dominant species at lower $\mathrm{HCl}$ concentrations resulting from the strong propensity for $\mathrm{GaCl}_{3}$ to hydrolyse at low acid concentrations; the degree of which can be calculated. ${ }^{112-114}$ Tetrachlorogallate(III) anions, $\left[\mathrm{GaCl}_{4}\right]^{-}$, are reported to be extracted via solvent extraction with a proton with TOPO at high acid concentrations. However, in order to unveil the underlying extraction mechanism in the case of $\chi_{\text {TOPO }}$ $=0.67$ TOPO:malonic acid both the content of water in the organic phase and whether or not $\mathrm{HCl}$ is exchanged with the carboxylic acid of the extractant following pre-equilibration should be followed in the future.
Under the conditions optimised by Sato et al. $(6 \mathrm{M} \mathrm{HCl}$, $\left.20{ }^{\circ} \mathrm{C}\right),{ }^{31}$ TOPO concentration is limited by its solubility in benzene, and the single contact distribution ratio was $c a$. $\mathrm{D}_{\mathrm{Ga}}=$ 1.3 (as read from a log graph reported). However, upon reproducing this experiment, the maximum benchmark singlecontact gallium extraction efficiency was $66 \%\left(D_{\mathrm{Ga}}=1.96\right)$. Noteworthy, the literature value was calculated from Eq. 8 ( $\mathrm{Ga}_{\text {org }}$ is the concentration of gallium in the organic phase, $\mathrm{Ga}_{\mathrm{aq}}$ is the concentration of gallium in the aqueous phase), for which [Gaorg] was quantified by stripping the organic phase with acidified aqueous phase, and subsequent measurement of gallium concentration in the aqueous phase. This assumes that no gallium remained in the organic phase.

$$
\mathrm{D}_{\mathrm{Ga}}=\frac{\left[\mathrm{Ga}_{\mathrm{org}}\right]}{\left[\mathrm{Ga}_{\mathrm{aq}}\right]}
$$

$D_{G a}$ was calculated as from Eq. 9. This assumes equilibrium mass transfer and no significant change in liquid volume as the gallium content in the organic phase was not measured directly.

The value of $\mathrm{D}_{\mathrm{Ga}}=1.96$ was used as a benchmark. Following reproduction of the benchmark experiment (TOPO in benzene), the $\chi_{\text {TOPO }}=0.67$ TOPO:malonic acid mixture was tested under identical conditions. As expected, all gallium was extracted from aqueous feeds at acid concentrations of $4 \mathrm{M} \mathrm{HCl}$ and above (to the detection limit of $0.1 \mathrm{ppm}$ ). These results primarily arise from a significantly greater concentration of TOPO in the eutectic extracting phase compared to the benchmark TOPO in benzene solution, which demonstrates validity of this approach.

Given that complete extraction of gallium was achieved using the $\chi_{\text {TOPO }}=0.67$ TOPO: malonic acid liquid extractant and the large excess of TOPO present in the liquid, the loading capacity of the extractant was studied. The results of $\chi_{\text {TOPO }}=0.67$ TOPO:malonic acid loading capacity are shown in Table 9 and represent the amount of gallium extracted ( $\mathrm{mmol}$ ) per $\mathrm{mL}$ of extractant when contacted with concentrated $\mathrm{HCl}$ solutions containing ca. $0.5 \mathrm{M}$ gallium chloride.

Table 9. Amount of gallium extracted $(\mathrm{mmol})$ from the aqueous phase by $\chi_{\text {Topo }}=0.67$ TOPO:malonic acid when TOPO is in excess of gallium $\left(\left[\mathrm{GaCl}_{3}\right]=0.006 \mathrm{M}\right)$ and when gallium is in excess of TOPO $\left(\left[\mathrm{GaCl}_{3}\right]=0.504 \mathrm{M}\right)$. Ambient temperature, pre-contact time: 10 mins, extraction time: 10 mins. When $\left[\mathrm{GaCl}_{3}\right]_{\mathrm{aq}}=0.006 \mathrm{M}$, org:aq $=1: 1$. When $\left[\mathrm{GaCl}_{3}\right]_{\mathrm{aq}}$ $=0.504 \mathrm{M}$, org: $\mathrm{aq}=1: 5 . \mathrm{D}_{\mathrm{Ga}}$ are gallium distribution coefficient estimates.

\begin{tabular}{cccc}
\hline Initial $\left[\mathrm{GaCl}_{3}\right]_{\mathrm{aq}} / \mathbf{M}$ & {$[\mathrm{HCl}] / \mathbf{M}$} & Ga extracted / $\mathbf{M}$ & $\mathbf{D}_{\mathrm{Ga}}$ \\
\hline 0.00568 & 1 & 0.00294 & 0.98 \\
& 5 & 0.00502 & 3499 \\
& 6 & 0.00562 & 3914 \\
& 8 & 0.00516 & 3599 \\
\hline 0.504 & 1 & 0.792 & 0.51 \\
& 5 & 1.18 & 1.35 \\
& 6 & 1.34 & 1.53 \\
& 8 & 1.28 & 1.37 \\
\hline
\end{tabular}

When the literature benchmark was replicated using $0.004 \mathrm{M}$ TOPO dissolved in benzene and contacted $6 \mathrm{M} \mathrm{HCl}$ containing $0.00568 \mathrm{M} \mathrm{GaCl}_{3}, 0.00372 \mathrm{mmol} \mathrm{mL}^{-1}$ gallium was extracted. The results show that the loading capacity of the $\chi_{\text {TOPO }}=0.67$ TOPO:malonic acid extractant is approximately 3 orders of magnitude greater than that achieved by the literature 
benchmark under the same conditions (i.e. 0.00372 and $1.34 \mathrm{mmol} \mathrm{mL}^{-1}$ respectively). This suggests that the $\chi_{\text {TOPO }}=0.67$ TOPO:malonic acid extractant has the potential to be used in multiple stage contact during extraction due to its large loading capacity.

\section{Conclusions}

Mixtures of TOPO with HBDs were screened to identify those that yield room-temperature liquids, with the potential for applications in separations. A range of such mixtures were identified, and from these two systems were selected for indepth study: TOPO:malonic acid and TOPO:levulinic acid; the former of interest for bifunctional gallium extraction, the latter potentially useful for the separation of levulinic acid from bioderived mixed feeds.

Thermal analysis of TOPO:malonic acid and TOPO:levulinic acid mixtures give valuable insight into operational condition limits. It was shown that, depending on thermal decomposition pathway, the presence of TOPO can decrease or increase thermal stability of the acid component. Phase diagrams were dependent on the acid structure: TOPO:malonic acid exhibited simple eutectic behaviour, ${ }^{92}$ in which the components did not form a compound and were miscible and immiscible in the liquid and solid phases respectively. Similarly, TOPO:levulinic acid had a solid liquid equilibrium where the components did not form a compound and were miscible in the liquid phase, however, in contrast to the TOPO:malonic acid phase diagram, components were partly miscible in the solid phase, therefore exhibiting a $2-1 \mathrm{II}_{\mathrm{a}}$ type phase diagram. ${ }^{92}$ The lowest-transition composition was $\chi_{\text {TOPO }}=0.55$ in TOPO: malonic acid, however, it must be noted that $\chi_{\text {TOPO }}=0.60$ acted as a glass and therefore did not exhibit a melting, but instead exhibited glass softening in the heating cycle. TOPO:levulinic acid's lowest transition composition was $\chi_{\text {TOPO }}=0.40$

When considering applications in extraction, a rational approach is to work with compositions that have high percentage of TOPO and yet remain liquid at ambient temperature, rather than with eutectic compositions. Using ${ }^{31} \mathrm{P}$ NMR spectroscopy, it was shown that such TOPO-rich compositions have stronger interactions with HBDs, and therefore should limit leaching of the HBD component to the aqueous phase. This was confirmed with leaching studies which indicated that higher $\chi_{\text {TOPO }}$ values resulted in lower leaching levels to both a water phase and a $6 \mathrm{M} \mathrm{HCl}$ aqueous phase independently. Unfortunately, leaching increased with increasing acidity of the aqueous phase. From density studies, TOPO-rich mixtures have lower density, which could enhance phase separation from water. Finally, depending on the process, maximising TOPO concentration might be beneficial for extraction efficiency.

In conclusion, this work proposes a new route to bifunctional, liquid, solvent-free extracting agents, underpinned with useful physico-chemical insights to guide future formulations. It is expected for this physical chemistry study to inspire further investigation into TOPO mixtures for metal

separations, extraction of platform bio-chemicals from aqueous feeds, and even nanoparticle synthesis.

\section{Conflicts of interest}

There are no conflicts to declare.

\section{Acknowledgements}

Solvay is kindly acknowledged for providing TOPO and DfE acknowledged for PhD funding (EB).

\section{Notes and references}

M. A. R. Martins, S. P. Pinho and J. A. P. Coutinho, J. Solut. Chem., 2019, 48, 962-982.

Q. Zhang, K. De Oliveira Vigier, S. Royer and F. Jérôme, Chem. Soc. Rev., 2012, 41, 7108-7146.

M. Francisco, A. van den Bruinhorst and M. C. Kroon, Angew. Chem. Int. Ed., 2013, 52, 3074-3085.

E. L. Smith, A. P. Abbott and K. S. Ryder, Chem. Rev., 2014 114, 11060-11082.

A. P. Abbott, G. Capper, D. L. Davies, R. K. Rasheed and V. Tambyrajah, Chem. Commun., 2003, 1, 70-71.

A. P. Abbott, D. Boothby, G. Capper, D. L. Davies and R. Rasheed, J. Am. Chem. Soc, 2004, 126, 9142-9147.

Q. Zeng, Y. Wang, Y. Huang, X. Ding, J. Chen and K. Xu, Analyst, 2014, 139, 2565-2573.

I. M. Pateli, K. Binnemans, N. Rodriguez and A. P. Abbott, RSC Adv., 2020, 10, 28879-28890.

M. Gilmore, L. M. Moura, A. H. Turner, M. Swadźbakwaśny, S. K. Callear, J. A. Mc Cune, O. A. Scherman and J. D. Holbrey, J. Chem. Phys., 2018, 148, 193823-193833. C. Florindo, A. J. S. McIntosh, T. Welton, L. C. Branco and I. M. Marrucho, Phys. Chem. Chem. Phys., 2018, 20, 206-213. C. F. Araujo, J. A. P. Coutinho, M. M. Nolasco, S. F. Parker, P. J. A. Ribeiro-Claro, S. Rudic, B. I. G. Soares and P. D. Vaz, Phys. Chem. Chem. Phys., 2017, 19, 17998-18009.

S. L. Perkins, P. Painter and C. M. Colina, J. Chem. Eng. Data, 2014, 59, 3652-3662.

D. V Wagle, G. A. Baker and E. Mamontov, J. Phys. Chem. Lett., 2015, 6, 2924-2928.

C. R. Ashworth, R. P. Matthews, T. Welton and P. A. Hunt, Phys. Chem. Chem. Phys., 2016, 18, 18145-18160.

O. S. Hammond, D. T. Bowron and K. J. Edler, Green Chem., 2016, 18, 2736-2744.

R. Stefanovic, M. Ludwig, G. B. Webber, R. Atkin and A. J. Page, Phys. Chem. Chem. Phys., 2017, 19, 3297-3306.

D. J. G. P. van Osch, L. F. Zubeir, A. van den Bruinhorst, M. A. A. Rocha and M. C. Kroon, Green Chem., 2015, 17, 45184521.

B. D. Ribeiro, C. Florindo, L. C. Iff, M. A. Z. Coelho and I. M. Marrucho, ACS Sustain. Chem. Eng., 2015, 3, 2469-2477. D. J. G. P. van Osch, D. Parmentier, C. H. J. T. Dietz, A. van den Bruinhorst, R. Tuinier and M. C. Kroon, Chem. 
Commun., 2016, 52, 11987-11990. M. J. Kaul, D. Qadah, V. Mandella and M. L. Dietz, RSC Adv., 2019, 9, 15798-15804.

21 E. E. Tereshatov, M. Y. Boloeva and C. M. Folden III, Green Chem., 2016, 18, 4616-4622.

S. Ruggeri, F. Poletti, C. Zanardi, L. Pigani, B. Zanfrognini, E. Corsi, N. Dossi, M. Salomaki, H. Kivela, J. Lukkari and F. Terzi, Electrochim. Acta, 2019, 295, 124-129. T. E. Phelps, N. Bhawawet, S. S. Jurisson and G. A. Baker, ACS Sustain. Chem. Eng., 2018, 6, 13656-13661.

C. Florindo, L. C. Branco and I. M. Marrucho, Fluid Phase Equilib., 2017, 448, 135-142. T. Krízek, M. Bursová, R. Horsley, M. Kuchar, P. Tuma, R. Cabala and T. Hlozek, J. Clean. Prod., 2018, 193, 391-396. 2017, 152, 399-405. Chem., 2018, 20, 1879-1886.

J. Cao, M. Yang, F. Cao, J. Wang and E. Su, ACS Sustain. Chem. Eng., 2017, 5, 3270-3278.

E. L. P. de Faria, R. S. do Carmo, A. F. M. Cláudio, C. S. R. Freire, M. G. Freire and A. J. D. Silvestre, Int. J. Mol. Sci., 2017, 18, 2276-2285.

Y. P. A. Silva, T. A. P. C. Ferreira, G. Jiao and M. S. Brooks, J. Food Sci. Technol., 2019, 56, 1649-1654.

T. Sato, T. Nakamura and S. Ishikawa, Solvent Extr. Ion Exch., 1984, 2, 201-212.

E. K. Watson and W. A. Rickelton, Solvent Extr. Ion Exch., 1992, 10, 879-889.

3 P. O. Saboe, L. P. Manker, W. E. Michener, D. J. Peterson, D. G. Brandner, S. P. Deutch, M. Kumar, R. M. Cywar, B. G. T.; and E. M. Karp, Green Chem., 2018, 20, 1791-1804. T. Brouwer, M. Blahusiak, K. Babic and B. Schuur, Sep. Purif. Technol., 2017, 185, 186-195.

G. Kim, S. Park and B. Um, Ind. Crop. Prod., 2016, 89, 3444.

S. Uenoyama, T. Hano, M. Hirata and S. Miura, J. Chem. Technol. Biotechnol., 1996, 67, 260-264.

P. Praveen and K. C. Loh, Chem. Eng. J., 2014, 255, 641649.

P. Praveen and K. Loh, Chemosphere, 2016, 153, 405-413.

P. Praveen and K. Loh, J. Membr. Sci., 2013, 437, 1-6.

E. K. Watson, W. A. Rickelton, A. J. Robertson and T. J. Brown, Solvent Extr. Ion Exch., 1988, 6, 207-220.

C. Bayliss and K. Langley, Nuclear decommissioning, waste management, and environmental site remediation,

Elsevier, 2003.

W. Jianchen and S. Chongli, Solv. Extn. Ion Exch., 2001, 19, 231-242.

F. Coleman, G. Srinivasan and M. Swadzba-Kwasny, Angew. Chem. Int. Ed., 2013, 52, 12582-12586.

J. M. Hogg, L. C. Brown, K. Matuszek, P. Latos, A. Chrobok and M. Swadźba-Kwaśny, Dalt. Trans., 2017, 46, 1156111574.

J. M. Hogg, F. Coleman, A. Ferrer-ugalde, M. P. Atkins and M. Swadźba-kwaśny, Green Chem., 2015, 17, 1831-1841. K. Matuszek, A. Chrobok, J. M. Hogg, F. Coleman and M.
Swadźba-kwaśny, Green Chem., 2015, 17, 4255-4262. A. van den Bruinhorst, S. Raes, S. A. Maesara, M. C. Kroon, A. C. C. Esteves and J. Meuldijk, Sep. Purif. Technol., 2019, 216, 147-157.

M. Gilmore, É. N. Mccourt, F. Connolly, P. Nockemann, M. Swadźba-kwaśny and J. D. Holbrey, ACS Sustain. Chem. Eng, 2018, 6, 17323-17332.

J. Beare-Rogers, A. Dieffenbacher and J. V Holm, Pure Appl. Chem., 2001, 73, 685-744.

T. K. Ng and J. G. Zeikus, Appl. Environ. Microbiol., 1986, 52, 902-904.

\section{5-42.}

J. A. Bis, P. Vishweshwar, D. Weyna and M. J. Zaworotko, Mol. Pharm., 2007, 4, 401-416.

T.-H. Lee, J.-L. Chiou, C.-K. Lee and Y.-H. Kuo, J. Chin. Chem. Soc., 2005, 52, 833-841.

E. Berlinger, F. Berlinger and I. Nelidow, J. Am. Chem. Soc., 1954, 76, 507-509.

K. W. Anderson, T. Ikawa, R. E. Tundel and S. L. Buchwald, J. Am. Chem. Soc, 2006, 128, 10694-10695. G. A. Olah, G. K. S. Prakash, P. S. Iyer, M. Tashiro and T. Yamato, J. Org. Chem., 1987, 52, 1881-1884.

A. Metzger, S. Bernhardt, G. Manolikakes and P. Knochel, Angew. Chem. Int. Ed, 2010, 49, 4665-4668. L. J. Reed and C. Niu, J. Am. Chem. Soc., 1955, 77, 416-419. S. G. Morris, J. Am. Chem. Soc., 1949, 71, 2056-2057. M. Piattelli, E. Fattorusso, S. Magno and R. A. Nicolaus, Tetrahedron, 1963, 19, 2061-2072. L. M. Fuentes and G. L. Larson, Tetrahedron Lett., 1982, 23, 271-274.

K. Bica and R. D. Rogers, Chem. Commun., 2010, 46, 12151217.

W. D. Shrader, J. Celebuski, S. J. Kline and D. Johnson, Tetrahedron Lett., 1988, 29, 1351-1354.

Z. Hou, K. Takamine, O. Aoki, H. Shiraishi, Y. Fujiwara and H. Taniguchi, J. Org. Chem., 1988, 53, 6077-6084. J. Nicolas, C. Billaud, J. Philippon and R.-M. M. A, in Encyclopedia of Food Sciences and Nutrition (Second Edition), ed. B. Caballero, Academic Press, 1982, pp. 678686.

L. Chun-Chen and R. K. Peddinti, Acc. Chem. Res., 2002, 35, 856-866.

R. Dawson and J. M. Nelson, J. Am. Chem. Soc., 1938, 60, 245-249.

D. Magdziak, R. A. A, R. W. van de Water and P. T. R. R, Org Lett. 2002, 2002, 4, 285-288.

P. De La Breteque, M. Beerli, U.S. pat. 3,887,681, 1975.

E. Uhlemann and W. Mickler, Anal. Chim. Acta, 1981, 130, 177-182.

Z. Zhao, Y. Yang, Y. Xiao and Y. Fan, Hydrometallurgy, 2012, 125-126, 115-124.

Y. Hasegawa, T. Shimada and M. Niitsu, J. Inorg. Nucl. Chem., 1980, 42, 1487-1489.

I. Mihaylov and P. A. Distin, Hydrometallurgy, 1992, 28, 1327.

D. W. Rackemann, W. O. S. Doherty and T. Crops, Biofuels, 
Bioprod. Bioref., 2011, 5, 198-214. F. D. Pileidis and M. Titirici, ChemSusChem, 2016, 9, 562582. J. J. Bozell and G. R. Petersen, Green Chem., 2010, 12, 539554.

O. V Kotova, S. V Eliseeva, A. A. Volosnikov, V. A. Oleinikov, L. S. Lepnev, A. G. Vitukhnovskii and N. P. Kuz'mina, Russ. J. Coord. Chem., 2006, 32, 901-909.

V. L. Stanford and S. Vyazovkin, Ind. Eng. Chem. Res., 2017, 56, 7964-7970. C. N. Hinshelwood, J. Chem. Soc. Trans., 1920, 117, 156165. J. Györe and M. Ecet, J. Therm. Anal., 1970, 2, 397-409.

81 A. M. El-Awad and R. M. Mahfouz, J. Therm. Anal., 1989, 35, 1413-1421. W. Wendlandt and J. A. Hoiberg, Anal. Chim. Acta 1963, 28, 506-511. S. Gál, T. Meisel and L. Erdey, J. Therm. Anal., 1969, 1, 159170.

N. R. Rodriguez, A. van den Bruinhorst, L. J. B. M. Kollau, M. C. Kroon and K. Binnemans, ACS Sustain. Chem. Eng, 2019, 7, 11521-11528. . Blake and G. E. Jackson, J. Chem. Soc. B, 1968, 11531155.

pp. 483-553.
E. Y. Tupikina, M. Bodensteiner, P. M. Tolstoy, G. S. Denisov and I. G. Shenderovich, J. Phys. Chem. C, 2018, 122, 17111720. M. Grilc and B. Likozar, Chem. Eng. J., 2017, 330, 383-397. M. Renz, Eur. J. Org. Chem., 2005, 979-988. J. Gmehling, B. Kolbe, M. Kleiber and J. Rarey, Chemical Thermodynamics for Process Simulation, Wiley, New York, 2012. J. A. P. Coutinho, S. I. Andersen and E. H. Stenby, Fluid Phase Equilib., 1995, 103, 23-39. J. Nývlt, Solid-Liquid Phase Equilibria, Elsevier Scientific Pub. Co., Amsterdam, 1977.

. Maximo, M. C. Costa and A. J. A. Meirelles, Phys. Chem. Chem. phys., 2014, 16, 16740-16754. B. Predel, M. Hoch and M. J. Pool, in Phase Diagrams and Heterogeneous Equilibria, Springer-Verlag Berlin Heidelberg, 2004, pp. 17-87. J. Kříž, J. Dybal, E. Makrlík, J. Budka and P. Vaňura, J. Phys. Chem. A, 2009, 113, 5896-5905. U. Mayer, V. Gutmann and W. Gerger, Monatsh. Chem., 1975, 106, 1235-1257. M. A. Beckett, G. C. Strickland, J. R. Holland and S. Varma, Polymer (Guildf)., 1996, 37, 4629-4631.

1126-1138.

99 K. A. Al-Farhan, Acta Cryst., 2003, C59, 179-180.

100 K. A. Al-Farhan, Acta Cryst., 2004, C60, 531-532.

101 D. B. Chesnut and A. Savin, J. Am. Chem. Soc., 1999, 121, 2335-2336.

102 K. A. Lyssenko, G. V Grintselev-knyazev and M. Y. Antipin, Mendeleev Commun., 2002, 12, 128-130.
H. Guerrero, C. Lafuente, F. Royo, L. Lomba and B. Giner, Energy Fuels, 2011, 25, 3009-3013.

G. Ghersini, in Extraction Chromatography, eds. T. Braun and G. Ghersini, Elsevier, 1975, pp. 68-133.

J. M. Warden and C. J. King, J. Chem. Eng. Data, 1978, 23, 144-148.

S. H. Yalkowsky and R. Dannenfelser, 1992.

E. chemical Agency, ECHA, Regist. Subst. Doss.

B. Gupta, N. Mudhar, Z. Begum I and I. Singh,

Hydrometallurgy, 2007, 87, 18-26.

A. K. De and U. S. Ray, Sep. Sci., 1972, 7, 409-417.

T. Katsura and H. Abe, U.S. Pat. 3;920;450, 1975.

L. A. Woodward and A. A. Nord, J. Chem. Soc., 1956, 37213722.

P. F. M. van Gaans, H. A. J. Oonk and G. Somsen, J. Solut. Chem., 1990, 19, 831-854.

X. Lu, L. Wang, X. Wang and X. Niu, Nonferrous Mat., 2008, 60, 105-108.

B. Das, R. N. Roy, K. S. Pitzer, D. R. Gregory and S. A. Kiefer, J. Solut. Chem., 2000, 29, 289-297. 